\title{
Die Odonaten der Kleinen Sunda-Inseln
}

von

\section{A. LIEFTINCK}

(Zoologisches Museum, Buitenzorg.)

Mit 19 Textfiguren.

Unsere Kenntnis der Odonatenfauna der Kleinen Sunda-Inseln war bisher - und ist eigentlich auch jetzt noch - sehr lückenhaft. Freilich haben gegen Ende des vorigen Jahrhunderts verschiedene zoologische Sammler, wie Elbert, Everett, Grelak und ganz besonders Fruhstorfer und Pagenstechfr auf Lombok, Flores und Soemba entomologisch gesammelt und dabei auch ein recht bemerkenswertes Odonatenmaterial zusammengebracht; die Ausbeuten wurden aber auf verschiedene europäische Museen verteilt und niemals zusammenfassend bearbeitet. Es ist ganz sicher, dass ein recht erheblicher Teil dieses Materiales noch unbeachtet in einer Anzahl Museen auf einen Bearbeiter wartet, und es erscheint sehr bedauerlich, dass z. B. die ausserordentlich reichhaltige Sammlung Fruhstorfers damals nicht als Ganzes beisammen geblieben ist.

Über die Geschichte der odonatologischen Erforschung dieser Inseln ist dementsprechend nur wenig zu sagen. Abgesehen von einer Reihe kleinerer Arbeiten, meist Neubeschreibungen oder Notizen über einzelne Arten enthaltend, von Förster, KrüGer, Mclachlan, Ris, E. Schmidt und dem Verfasser, wurde bisher noch kein Versuch gemacht, ein Verzeichnis aller von dieser Inselkette bekannt gewordenen Odonatenspecies aufzustellen. In der grundlegenden Monographie der Unterfam. Libellulinae von F. Ris, die von 1909 bis 1916 erschienen ist, wurde zum ersten Male 
für eine bestimmte Gruppe ein vollständiges Verzeichnis der bekannten Arten gegeben. Über die Verteilung der einzelnen Formen auI̊ den Kleinen Sunda-Inseln ist dabei zu erwähnen, dass für Bali noch keine, für Lombok 13, für Soembawa 6, für Flores 8, für Soemba 10, für Timor 7, für Alor 2 Arten, und für Sawoe, Pantar und Kisar je eine Libellulinenart angeführt wurden. Hieraus ergibt sich wohl, dass sogar von den im ganzen recht gut bekannten und weit verbreiteten Libellulinen $\mathrm{zu}$ dieser Zeit nur eine ganz geringe Anzahl Arten nachgewiesen, und dass wir von einer wirklich erschöpfenden Kenntnis der Odonatenfauna dieser Inseln doch noch recht weit entfernt waren. Völlig unzureichend waren aber unsere Kenntnisse der anderen Familien, besonders diejenige über die Agrioniden, Gomphiden, Corduliinen und Aeschniden.

Obwohl kürzlich von Scнмid tie ersten 9 Arten von der Insel Bali nachgewiesen wurden ${ }^{1}$, können wir auch heute noch mit Recht sagen, dass Bali wie Robert Mertens einmal ganz richtig betont hat ${ }^{2}$ "dessen genaueste faunistische Erforschung für die Beurteilung der 'WALlaceschen Linie' natürlich ebenso wichtig ist wie die von Lombok ", fast ganz terra incognita geblieben ist. Dieses Material setzt sich nämlich ausschliesslich aus zoogeographisch wenig bemerkenswerten, im westlichen Teile des Archipels weitverbreiteten Arten zusammien.

Bei Anfang unserer Bearbeitung waren von den in Frage stehenden Inseln die folgenden Zahlen von Libellenarten bekannt (die neulich vom Verfasser in einer Reihe kleinerer Schriften angeführten oder neubeschriebenen Arten sind hier nicht miteinbezogen):

\begin{tabular}{|c|c|c|c|c|c|c|c|c|c|c|}
\hline 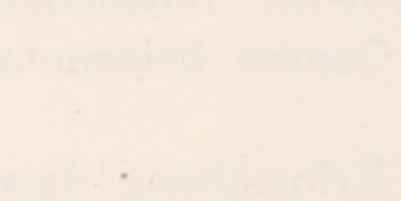 & :ేశ & $\begin{array}{l}\frac{10}{0} \\
\text { है } \\
0\end{array}$ & 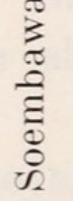 & 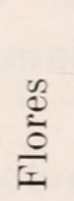 & 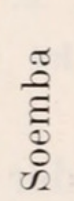 & $\begin{array}{l}\stackrel{\Xi}{g} \\
\Xi\end{array}$ & 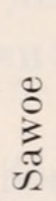 & $\begin{array}{l}\underset{\tilde{J}}{\tilde{\Xi}} \\
\text { ص. }\end{array}$ & $\stackrel{\check{\sigma}}{4}$ & 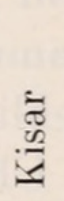 \\
\hline Zygoptera . . . & 3 & 3 & 0 & 2 & 3 & 2 & 0 & 0 & 0 & 0 \\
\hline Anisoptera... & 7 & 18 & 7 & 10 & 11 & 8 & 1 & 1 & 2 & 1 \\
\hline Total & 10 & 21 & 7 & 12 & 14 & 10 & 1 & 1 & 2 & 1 \\
\hline
\end{tabular}

1 Odonata der Deutschen limnologischen Sunda-Expedition, I. Archiv f. Hydrobiol., Suppl., Bd. XIII, 1934.

${ }_{2}$ Die Amphibien und Reptilien der Inseln Bali, Lombok, Sumbaxa und Flores. Abh. Senckenb. Naturf. Ges., 42, 1930. 
In der vorliegenden Darstellung sollen nun sämtliche bisher auf den Inseln Bali, Lombok, Soembawa, Flores, Soemba, Timor und benachbarten Inselchen nachgewiesenen Odonaten in systematischer Folge aufgezählt und mit einer Ordnungsnummer versehen werden. Obwohl ich nicht dafür einstehen kann, dass mir gar nichts entgangen sei, wurde alles aufgenommen, was ich in der zugänglichen Literatur über Odonaten der Kleinen Sunda-Inseln finden konnte. Ausserdem habe ich mich bemüht, alle Angaben über Nomenklatur und Synonymie mit aufzunehmen, so dass die folgende kleine Arbeit als ein möglichst vollständiger Katalog dieser Fauna gelten kann. Zweifelsfälle sind entweder ganz fortgelassen, oder als solche ausdrücklich erwähnt und doch aufgenommen.

In der Hauptsache stützt sich die vorliegende Bearbeitung auf folgende drei verschiedenen Ausbeuten rezenten Datums:

1. Die Ausbeute der Studienreise Prof. Dr. Ed. Handschins auf den Kleinen Sunda-Inseln Bali, Soembawa, Soemba, Flores und Timor 1931-1932;

2. Die Odonaten der Soemba-Expedition des Zoologischen Museums in Buitenzorg 1925, gesammelt von Dr. K. W. DAMMERMAN ${ }^{1}$;

3. Die Odonaten der Niederländisch-amerikanischen Forschungsreise nach Westflores 1929, gesammelt von Dr. J. K. DE Jong.

Die Odonatensammlung der Soemba-Expedition 1925 war zur Zeit der Ausführung der Reise der erste etwas grössere Beitrag zur Kenntnis der Libellenfauna jener wenig erforschten Insel; nicht weniger als 24 Species, darunter 4 neue Arten und 3 neue Rassen sind darin vertreten. Dasselbe gilt zweifellos für die 26 Arten enthaltende, Ende 1929 von der Insel Flores heimgebrachte Sammlung, mit 1 neuen Art und 2 neuen Rassen. Schliesslich ist es Prof. Handschin's eifriger Sammeltätigkeit zu verdanken, dass wir jetzt auch über die Zusammensetzung der Inselfauna von Bali, Soembawa und vor allem Timor etwas besser unterrichtet worden sind. Von den 26 aufgefundenen Arten haben sich 2 Species und 3 Rassen als neu erwiesen.

Ausser diesen drei Hauptsammlungen stand mir auch noch

1 Reisebericht: K. W. Dammerman, Een tocht naar Soemba. Indisch Comité voor Wetenschappelijke onderzoekingen. Batavia, 1926. 
schönes, z. T. unbearbeitetes Material aus den Hamburger und Brüsseler Museen zur Verfügung, sodann einige Odonaten, die von Prof. R. Woltereck während seiner Wallacea-Expedition 1932 auf Flores zusammengetragen wurden und die genannter Forscher mir freundlich zum Studium anvertraut hat. Es war schliesslich eine gegebene Sache, auch die wenigen in meiner eigenen Sammlung befindlichen Odonaten des Faunenbezirks und die des Buitenzorger Museums mit in Betracht zu ziehen, darunter auch eine kleine aber sehr interessante Sammlung Larven von verschiedenen Fundstellen, die ich u. a. Mrs. M. E. Walsh in Soekaboemi verdanke.

All dieses Material gestattet uns, einen freilich recht unvollständigen aber doch interessanten Überblick über die Odonatenfauna der Kleinen Sunda-Inseln zu geben. Auf die einzelnen Inseln verteilen sich die Species und Subspecies der insgesamt 63 bekannten Arten wie folgt:

\begin{tabular}{|c|c|c|c|c|c|c|c|c|c|c|}
\hline & $\cong$ & $\begin{array}{l}\frac{\pi}{0} \\
\text { है } \\
\stackrel{0}{0}\end{array}$ & 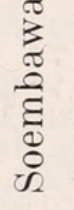 & 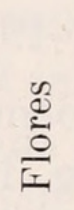 & 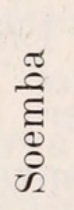 & 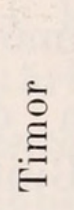 & 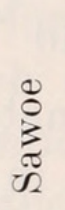 & 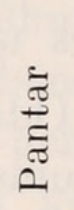 & $\frac{\tilde{\sigma}}{4}$ & 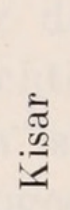 \\
\hline Zygoptera & 5 & 5 & 4 & 12 & 9 & 8 & 0 & 0 & 0 & 0 \\
\hline Anisoptera . . . & 14 & 18 & 9 & 22 & 21 & 13 & 1 & 1 & 2 & 3 \\
\hline Total . . & 19 & 23 & 13 & 34 & 30 & 21 & 1 & 1 & 2 & 3 \\
\hline
\end{tabular}

Eine erschöpfende geographische Analyse, wie es z. B. Robert Mertens für die Amphibien und Reptilien der Inseln Bali, Lombok, Soembawa und Flores gegeben hat (loc.cit.), würde mit unseren noch immer recht lückenhaften Kenntnissen der Fauna nicht befriedigend durchzuführen sein. Einige der auffallendsten Tatsachen seien hier aber kurz erwähnt:

Die Zahl von 63 bekannten Arten ist eine überaus geringe, wenn wir die grosse Ausdehnung des Gebietes berücksichtigen. Freilich muss hervorgehoben werden, dass auf den Kleinen Sunda-Inseln noch nie durch einen Odonatologen gründlich gesammelt wurde, wodurch vielleicht zu erklären ist, dass z. B. nur eine sehr geringe Anzahl weniger auffallender aber zoogeographisch eben recht wichtiger Formen aufgefunden wurde (Fehlen der Platystictidae, 
relativ geringe Anzahl Agrionidae, Corduliinae und Aeschnidae!). Aber doch ist, nach der ganzen Zusammensetzung der Listen, zu erwarten, dass deren geringem Umfang wirkliche Armut der Fauna zugrunde liegt. Wir nehmen mit vielen hervorragenden Autoren (Max Weber, R. Mertens, B. Rensch) an, dass für die Artenarmut der Kleinen Sunda-Inseln die relativ grosse Entfernung von den mächtigen Entwicklungszentren der indoaustralischen Fauna, sowie ihre kurze und recht wechselvolle, für eine reiche Entfaltung tierischen Lebens wenig günstige geologische Geschichte als wichtige Ursachen verantwortlich gemacht werden müssen.

\section{Endemische Formen.}

Trotz der Artenarmut finden sich auf den Kleinen Sunda-Inseln eine ziemlich grosse Anzahl endemischer Formen; endemische Genera gibt es unter den Odonaten aber nicht. Von 63 bekannten Arten sind sogar $12(19 \%)$ Species bisher nur auf diesen Inseln gefunden. Es sind folgende Arten: Euphaea lara, Rhinocypha pagenstecheri, R. sumbana, Libellago naias, Notoneura emphyla, $N$. diadesma, N. selysi, Pseudagrion calosomum, P. schmidtianum, Trithemis lilacina, Mesogomphus flavohamatus und M.tachyerges. Von diesen Endemismen entfallen auf die Zygoptera 9 und auf die Anisoptera 3 Arten. Unter den Zygopteren sind also, wie zu erwarten war, endemische Formen am häufigsten. Es ist beachtenswert, dass von diesen 12 endemischen Species wenigstens 2, nämlich Notoneura emphyla und diadesma, einem zweifellos aus dem Osten stammenden Typus angehören; vielleicht gilt dasselbe für die 2 neubeschriebenen Pseudagrion-Arten. Westliche endemische Arten sind wahrscheinlich Euphaea lara (Verwandtschaft nach E. Sснмірт mit $E$. variegata Rb., von Java, und vielleicht auch mit dem Formenkreis ochracea Selys, von Hinterindien und Malaya), Libellago naias (nächstverwandt mit L. sumatrana Sel.), Notoneura selysi und Trithemis lilacina (letztere zeigt Verwandtschaft mit T. festiva Rb.). Dabei ist zu bemerken, dass von der artenreichen, vorwiegend papuanischen Gattung Notoneura nur eine einzige Species, $N$. insignis (Sel.), über W a $1 \mathrm{l}$ a c e a hinaus in die malayische Subregion vorgedrungen ist, und eben diese zeigt mit N. selysi der Kleinen Sunda-Inseln die grösste Verwandtschaft. Die übrigen Arten, vor allem die beiden Rhinocypha- und die zwei 
Mesogomphus-Species, dürften jedoch nicht unmittelbar aus dem Westen gekommen sein, sondern ursprünglich von Celebes aus über die Saleyer-Brücke die Kleinen Sunda-Inseln erreicht und sich als selbständige Arten weiter entwickelt haben. R. pagenstecheri und sumbana bilden eine völlig isoliert stehende Gruppe, ausgezeichnet durch beträchtliche Grösse und sehr auffallende, vorwiegend rote Körperfärbung; merkwürdigerweise zeigen sie in diesem Punkt eine überraschende Habitusähnlichkeit mit einer Gruppe rotgezeichneter Libellago-Arten, welche auf die Insel Celebes beschränkt zu sein scheint. Die Mesogomphus-Arten zeigen mit dem einzigen Vertreter dieser Gattung auf Celebes, M. capitatus Martin, die meiste Verwandtschaft.

Die Zahl der endemischen Subspecies ist relativ gering; doch sind diese in vielen Fällen noch nicht eingehend untersucht worden; wenigstens 8 Rassen sind für die Inselgruppe bezeichnend: Euphaea lara balica, E. lara lombockensis, Rhinocypha pagenstecheri timorana, Pseudagrion pilidorsum declaratum, P. pilidorsum deflexum, Orthetrum testaceum soembanum, Rhyothemis phyllis subsp., und R. regia subspec.

\section{Beziehungen zu den indomalayischen und australischen Faunaregionen.}

Wie aus der Übersichtstabelle der Arten hervorgeht, spielt das orientalische Faunenelement im Gebiete der Kleinen Sunda-Inseln bei weitem die grösste Rolle. Von den 51 nichtendemischen, wenigstens auf e i n e r der Kleinen Sunda-Inseln vorkommenden Arten (nicht Subspecies!) kommen 44 (also über 86\%) auch auf Java vor ${ }^{1}$; der grösste Teil davon kommt nicht nur auf Java und den anderen Grossen Sunda-Inseln vor, sondern auch auf dem asiatischen Festlande oder östlich bis über die Grenzen der malayischen Subregion hinaus. Das Verbreitungszentrum einer Art, Pseudagrion pilidorsum, einer Agrionide, die sich auf den Kleinen Sunda-Inseln in einzelnen Rassen besonders reichlich entwickelt hat, ist nicht einwandfrei anzugeben, ebensowenig dasjenige von Xiphiagrion cyanomelas. Von den übrigen 6 Arten hat Rhyothemis regia (Soemba) eine diskontinuirliche, vorwiegend insuläre Ver-

1 Von Java sind jetzt insgesamt 141 Species bekannt (siehe Lieftinck, Treubia, 14, 1934). 
breitung (P. Weh an der Nordspitze Sumatras, Simaloer, Soemba, Molukken, Kei und Neuguinea) und ist zweifellos östlichen Ursprungs. Schliesslich sind es 4 Arten: Orthetrum caledonicum (Timor), Brachydiplax duivenbodei (Flores), Diplacodes haematodes (Timor) und Rhyothemis graphiptera (Timor), die auf den Kleinen Sunda-Inseln ihre Westgrenze erreichen.

Brachydiplax duivenbodei dürfte von den Molukken bzw. Neuguinea stammen und ist wahrscheinlich zunächst über die SARAsin'sche Molukken-Brücke (Boeroe!) nach Celebes (wo sie schon aufgefunden wurde!) und von dort über die Saleyer-Brücke zuerst nach Flores eigewandert. Als australische Elemente in der Fauna der Kleinen Sunda-Inseln kommen eigentlich nur Orthetrum caledonicum, Diplacodes haematodes und Rhyothemis graphiptera in Betracht; das Entwicklungszentrum dieser Arten liegt zweifellos in Australien, während ihr gesamtes Vorkommen auf Timor wahrscheinlich darauf hindeutet, dass sie direkt, also unmittelbar aus der östlichen Richtung, und nicht über die Saleyer-Brücke nach den Kleinen Sunda-Inseln gekommen sind. Es ist aber noch zu erwähnen, dass $R$. graphiptera auch auf Neuguinea, den Aroe-Inseln und den nördlichen Molukken (Boeroe), D. haematodes auch auf Neuguinea vorkommt.

Fassen wir auf Grund des bisher Erörterten die Resultate unserer allerdings recht provisorischen Analyse zusammen, dann lässt sich über die Verteilung der einzelnen Species und Subspecies über die Inseln noch Folgendes aussagen:

1. Die Kleinen Sunda-Inseln haben ihre Odonatenfauna von zwei Entwicklungszentren erhalten: von einem westlichen oder rein orientalischen, und einem östlichen, molukkisch-papuanischaustralischen Zentrum.

2. Die Anzahl westlicher Formen nimmt von Westen nach Osten allmählich ab (Bali 100\% - Euphaea lara und Hemicordulia spec. fraglich --, Lombok 70\%, Soembawa 63\%, Flores $61 \%$, Soemba 50\%, Timor 57\%); die Anzahl östlicher Formen ist sehr gering und nimmt von Osten nach Westen schnell ab (Timor $14 \%$ - Neurobasis fraglich —, Soemba 6,6\%, Flores 5,9\%).

3. Das endemische Element in der Fauna ist beträchtlich und zweifellos recht alt; der grösste Teil der endemischen Formen zeigt Verwandtschaft mit westlichen Typen. 
4. Nur die Odonatenfauna der Inseln Flores und Soemba ist verhältnismässig gut bekannt; nach diesen folgen Lombok und Timor, während die Inseln Bali und Soembawa, somit die kleineren Inselchen noch fast ganz unerforscht geblieben sind.

\section{ZYGOPTERA.}

\section{Fam. Calopterygidae.}

\section{Neurobasis chinensis subsp.?}

1854. Selys, Mon. Calopt., p. 75 sep. - Timor.

1897. Selys, Ann. Soc. ent. Belg. 41, p. 428. - Timor? (N. chin. race florida).

Die oben zitierte Literatur ist das einzige, was sich über das Vorkommen einer Neurobasis auf den Kleinen Sunda-Inseln aussagen lässt. Der Fundort Timor, in 1897 von SELYs mit Fragezeichen versehen, ist vielleicht falsch und bedarf sicher der Bestätigung. Da aber die Art in Neuguinea in veränderter Form wieder auftaucht, ist ihr Vorkommen in Timor gar nicht unwahrscheinlich.

\section{Fam. Euphaeidae.}

\section{2. a) Euphaea lara lara Krüger.}

(Fig. 1.)

1898. Krüger, Stett. ent. Zeitg. 59, p. 131-132. - ô Soemba (E. lara). 1898. McLachlan, Ent. Monthly Mag. (2) 9, p. 272. - ô Soemba (E. lara).

M a t e ri a l: 9 ô, 4 q, E. Soemba, Kananggar, 700 m, V. 1925, K. W. Dammerman leg.

Die typische Rasse ist bisher nur von der Insel Soemba bekannt geworden.

o. Sehr schön in den Farben erhalten. Mit der Originalbeschreibung in den meisten Punkten übereinstimmend. Eine Querader im $q$ ist bei allen Exemplaren vorhanden. Flügel etwas weniger intensiv braungelb gefärbt wie bei lara lombokensis, in der Mitte viel deutlicher verbreitert.

Färbung des Gesichtes hellgrün. Stirn nuur bei einem einzigen $\hat{o}$ an den vorderen Seitenecken sehr schmal grünlich, sonst ganz 
schwarz (bei $l$. lomb. mit vollständiger gelber Linie). Die Variabilität der Thoraxzeichnung ist nicht sehr bedeutend und sicher nur von der Ausfärbung abhängig. Maximale Ausdehnung der lichten Färbung siehe Figur 1. Bei $4 \hat{o}$ ist die antehumerale Binde oben (wie beim Typus) nicht mit der medialen verbunden, und bei 3 o ist auch die leicht gebogene, posthumerale Binde vom gelb der Thoraxseiten schmal schwarz getrennt. Bei den ältesten Stücken ist die isolierte braune Binde auf der Mitte des Metepimerums vergrössert und sehr scharf schwarz begrenzt.

o Alloty pe (unbeschrieben). - Gesicht wie bei l. lombokensis, Fleckenzeichnung der Oberlippe hellgrün, im übrigen ockergelb. Nur die Seitenecken der Stirn vor den Antennen gelb.

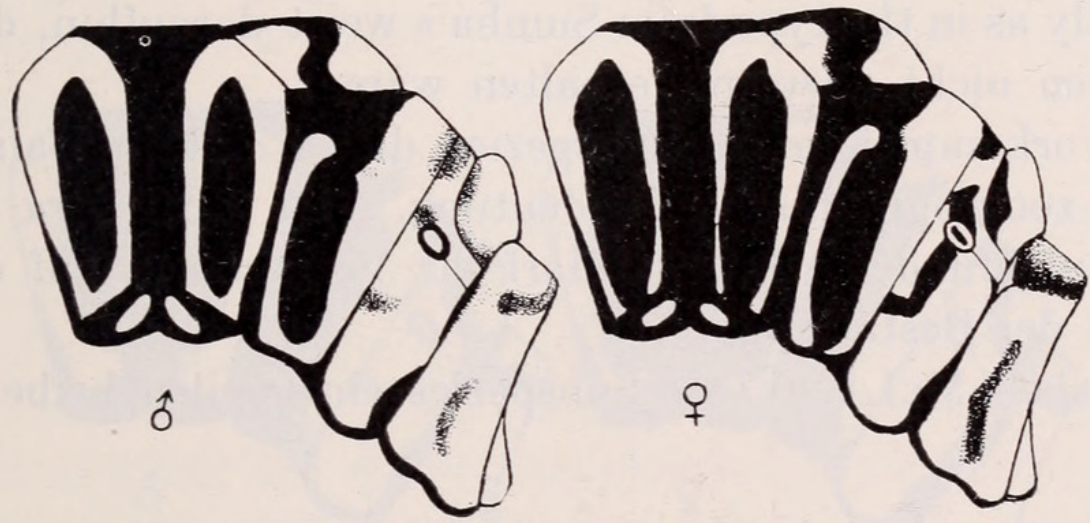

Fig. 1. - Euphaea lara lara Krüg., Soemba.

Thoraxzeichnung.

Erstes Antennenglied am Grunde gelb, sonst dunkelbraun. Zwischen der Basis der Antennen und dem hinteren Ocellus je ein hellgelber Fleck. Pro- und Synthorax wie beim ô (Fig. 1). Beine ebenso.

Flügel licht gelblich, distalwärts ganz diffus auslaufend; Flügelbasen etwas tiefer gelb, vor allem in $m$ und am Vorderrande. Pterostigma braun, unten mit lichterem Saum, 2,5 mm lang.

Abdomen wie für $l$. lombokensis beschrieben; die gelben Längsstreifen jedoch schmäler und apikal ganz verschwindend. Nur Segment 9 mit gelbem Seitenpunkt.

ô Abd. +App. 34-37, Hfl. 29-30; + 29-30, 28-28,5 mm.

Von dieser Art unterscheiden wir folgende Subspecies, von denen die auf Lombok, Soembawa und Flores anscheinend häufig vorkommende $E$. lara lombokensis hier besser begründet werden konnte. 


\section{2. b) Euphaea lara balica McLachlan.}

1898. McLachlan, Ent. Monthly Mag. (2) 9, p. 272. - ô Bali (E. lara var. balica).

Diese Rasse habe ich leider nicht mit dem Material der östlicheren Kleinen Sunda-Inseln vergleichen können. Nach McLachlan soll die balica sich nur durch ihre geringere Grösse von lara lara unterscheiden. Ausserdem hat der Autor nur ein einziges ô zur Verfügung gehabt (dazu mit zerbrochenem Abdomen!); es wurde angeblich von Dоневту gesammelt.

Als Mass eines Hinterflügels gibt McLachlan $28 \mathrm{~mm}$ an; das Stück ist also ziemlich klein. Die Notiz "markings of the thorax apparently as in the type from Sumba » weist daraufhin, dass auch die Farben nicht allzu gut erhalten waren.

Das Vorkommen einer Subspezies dieser Art in Bali ist von grösster zoogeographischer Bedeutung. Da aber lara dort nie wieder aufgefunden wurde, bedarf ihr Vorkommen auf der Insel dringend der Bestätigung.

Wir haben McLachlan's Subspezies einstweilen beibehalten.

\section{2. c) Euphaea lara lombokensis McLachlan.}

(Fig. 2.)

1898. McLachlan, Ent. Monthly Mag. (2) 9, p. 272-273. - ô Lombok (E. lara var. lombokensis).

1934. Schmid t, Arch. Hydrob., Suppl.-Bd. 13, p. 326-327. - ô Lombok.

M a t e ri a l: 27 ô, 7 क, Lombok, Sapit $600 \mathrm{~m}$ und Sambaloen 1200 m, IV. 1896, H. Fruhstorfer leg. (Mus. Hamburg). - 1 ô, 1 9 , Soembawa, H. Fruhstorfer leg., etikettiert: "Euphaea auripennis Selys, race de ochracea " (Handschrift von de Selys), ex Mus. Brüssel em. V. 1898 (Ms. Hamburg). -- 13 ô, 6 ㅇ, W. Flores, Wai Radjang, 140 m, 16.-18. XI. 1929, schnellfliessender Waldbach, und Naga, 220 m, 12. XI. 1929, idem, J. K. DE Jong leg.; 42 ô, 18 ㅇ, S. Flores, Rioeng Papang, Alo Wai Fluss, 28. IX. 1908, van der

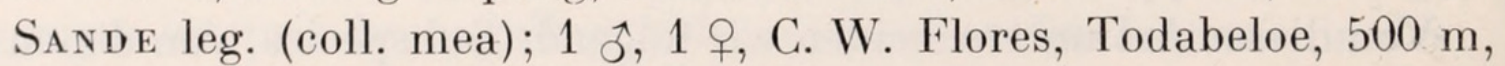
XII. 1931, Ed. Handschin leg.

Die sehr grosse Serie ist im Ganzen recht homogen. Exemplare von Lombok, Soembawa und Flores sind unter sich fast gleich. Die 
Unterschiede sind jedenfalls nicht von der Herkunft abhängig, sondern beziehen sich nur auf die mehr oder weniger grosse Ausdehnung der gelben Thoraxfiguren, die bei jungen Tieren schärfer begrenzt und erheblich mehr ausgedehnt erscheinen als bei adulten Exemplaren. Voll ausgefärbte ổ ŝ sind sowohl unter dem Material von Lombok als unter demjenigen von Flores vertreten, und diese sind gekennzeichnet durch starke Verdüsterung der gelben Zeichnungen, sodass in manchen Fällen nur ein schmaler, stark verdunkelter Streifen entlang der Humeralnaht übrig bleibt. Diese Binde ist medianwärts vielfach unscharf begrenzt (bisweilen in ihrem oberen Teil sogar ganz verschwommen), und in manchen Exemplaren fehlt die ventrale, nach aufwärts umbiegende, innere Fortsetzung vollständig. In unserer Figur 2 ist die Thoraxzeichnung

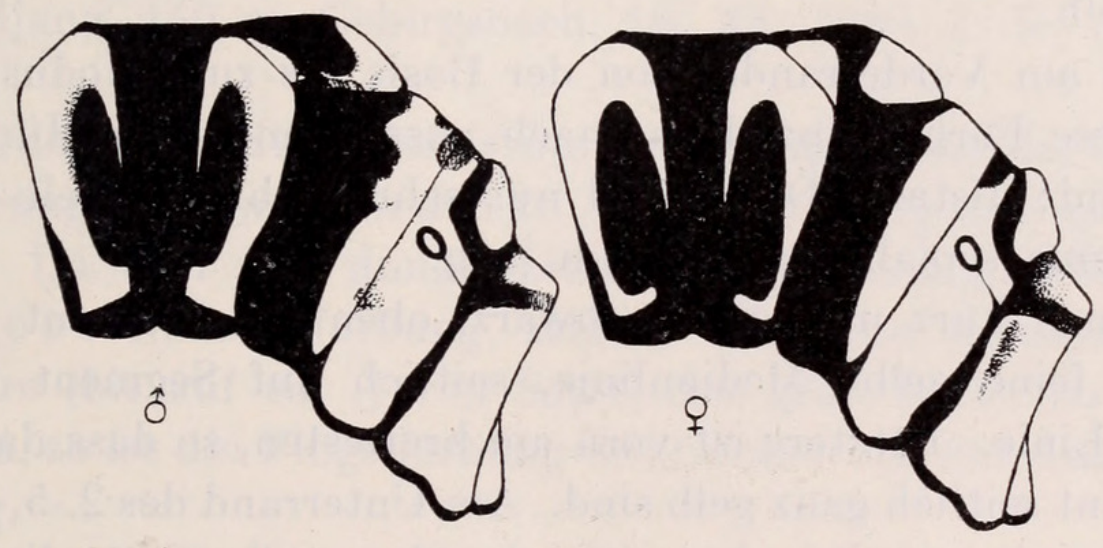

FIG. 2. - Euphaea lara lombockensis McLach., Flores.

Thoraxzeichnung.

eines wohl ausgefärbten aber noch nicht verdunkelten ô nach einem Exemplar von Flores wiedergegeben. Die schwarze Binde entlang der 2. Seitennaht kann sich bei älteren Exemplaren verbreitern, sodass das dorsal-vordere Drittel des Metepimerum ebenfalls ganz schwarz gefärbt ist.

Die Männchen von Lombok und das einzige von mir gesehene $\hat{\sigma}$ von Soembawa sind durchschnittlich ein wenig kleiner als die floresischen Stücke.

Das $q$ ist meines Wissens noch unbeschrieben.

ㅇ A 11 o t y p e (Flores; topotypische Exemplare zur Zeit nicht mehr vorliegend). - Unterlippe grünlichgelb, an den Spitzen 
schwarz. Kopf vorn wie beim $\hat{\jmath}$, aber die hell grünlichgelben Zeichnungen mehr ausgeprägt und vergrössert; die Färbung der Wangen reicht nach oben, entlang dem Augenrand, bis zum Niveau der Antennen, wo sie plötzlich aufhört, aber medianwärts durch ein breites gelbes Querband mit der Vorderseite der Stirn verbunden ist. Furche zwischen Clypeus und Frons flach-dreieckig, schwarz. Oberlippe durch eine schwarze Längslinie in zwei Hälften geteilt und ringsum schmal schwarz gesäumt. Auf der Stirn neben den Ocellen jederseits ein diffuser rötlicher Fleck.

Pro- und Synthorax wie beim jungen $\hat{o}$; alle Zeichnungen schärfer ausgeprägt und etwas vergrössert, hellgelb, oder mit schwach grünlicher Beimischung (Fig. 2). Ventralseite gelbbraun, mit blauer Bereifung.

Beine schwarzbraun; basale Hälfte der Mittel- und Hintertibien innen gelb.

Flügel am Vorderrande, von der Basis bis zum Nodus, kräftig gelb; diese Farbe ganz diffus nach aussen und zum Hinterrande auslaufend; distales Dreiviertel nur sehr leicht graugelb getrübt. Pterostigma sepiabraun, 2,8 $\mathrm{mm}$ lang.

Abdomen kurz und dick, schwarz, oben auf Segment 1-4 eine äusserst feine gelbe Medianlinie, seitlich auf Segment 1-6 eine breitere Linie. Letztere ist vorn am breitesten, so dass das 1. und 2. Segment seitlich ganz gelb sind. Am Unterrand des 2.-5. (oder 6.) Tergits ist eine zweite, aber viel schmälere gelbe Seitenlinie sichtbar, die aber nach hinten allmählich verschwindet. Entlang dem 6. Segment ist nur an der Basis und ganz am Ende ein schmaler Strich gelb. Segment 7-8 ganz schwarz, 9 seitlich mit grossem rundlichem Fleck vor dem Hinterrand, 10 und Appendices schwarz. Valven sehr kurz und schmal, wenig vorragend, gelbbraun.

Die übrigen $q$ unterscheiden sich nur durch etwas stärkere Ausbreitung der gelben Färbung am Thorax (antehumerale und mediale gelbe Binde oben fast zusammenhängend) und durch den Besitz eines gelben Seitenpunktes am Ende des 8. Segments.

ô Abd. + App. 33-37, Hfl. 28-31; o 28-29, 28-29 mm. 


\section{Fam. Libellaginidae.}

3. a) Rhinocypha pagenstecheri pagenstecheri Först.

(Fig. 3.)

1897. Förster, Ent. Nachr. 23, p. 333-335. - ơ오 Lombok (R. pagenstecheri). 1898. McLachlan, Ent. Monthly Mag. (2) 9, p. 273-274. - ôt Lombok (Libellago lombokensis).

1916. Ris, Entom. Mitteilungen, 5, p. 316-317 (Tabelle), 317. — đơ Lombok, ô S. Flores (excl. Soemba und Timor!) (R. pagenstecheri).

M a t e r i a 1: 8 ô, 1 क , Lombok, Sapit $600 \mathrm{~m}$, und 8 ô, 3 우, id., Sambaloen, 1200 m, IV. 1896, H. Fruhstorfer leg. (Mus. Hamburg). - 1 ô etikettiert: "Sumbawa, Fruhstorfer, ex Mus. Brüssel em. V. 1898, R. pagenstecheri ô Sumbawa» (Mus. Hamburg). - 1 \& (ad., in den Farben sehr gut erhalten), W. Flores, Wai Radjang, 140 m, Gebirgsbach, 18. XI. 1929, J. K. DE Jong leg.

Die vorliegenden Exemplare stimmen vorzüglich mit der Originalbeschreibung überein. Von den 16 o haben 8 völlig hyaline Flügelspitzen. Da aber alle dunkelspitzigen Männchen gleichfalls die adult rote Thoraxfärbung zeigen, und alle hyalinspitzigen Exemplare (bis auf ein $\hat{\sigma}$ von Sapit) eine gelbe Farbe des Thorax aufweisen, so ist die Flügelfärbung wohl sicher von der Ausfärbung abhängig.

Das einzige ơ von Soembawa ist von den anderen nicht verschieden; es hat auch dunkle Flügelspitzen.

Es ist sehr beachtenswert, dass beim ô nur die Appendices und das 10. Segment des Abdomens schwarz sind, während bei der unten beschriebenen Subspecies von Timor auch das 9. Segment schwarz ist.

ô Abd. 20-23, Hfl. 27; q 18-19,5, 27-28,5 mm.

Das $q$ von Flores stimmt in allen Einzelheiten mit dem im Original beschriebenen überein, nur ist es ein wenig kleiner: Abd. 19, Hfl. 25 mm. Thorax siehe Figur 3 (links).

3. b) Rhinocypha pagenstecheri timorana, subsp. n.

(Fig. 3.)

M a t e ri a l : 4 ô (1 juv.), 1 ㅇ, S. Timor, Koepang, XII. 1931I. 1932, Ed. Handschin leg. 
§. - Kopf sammtschwarz; gelb sind zwei in der Mitte deutlich voneinander getrennte, rechteckige Flecken auf der Stirn zwischen den Antennen; je ein kleinerer, halbmondförmiger Fleck jederseits neben den hinteren Ocellen; ein Punktfleck unmittelbar dahinter, und zwei wieder etwas grössere Postokularflecken. In der Furche zwischen Clypeus und Frons stehen einige gelbe Querstriche, während auch die Wangen und die Mandibelbasen gelb gefleckt sind. Oberlippe und Clypeus glänzend violettmetallisch. Antennen ganz schwarz.

Prothorax schwarz, reichlich gelb gefleckt: der ganze Vorderrand, zwei grosse, schief unter einander stehende Flecken auf den Seiten,
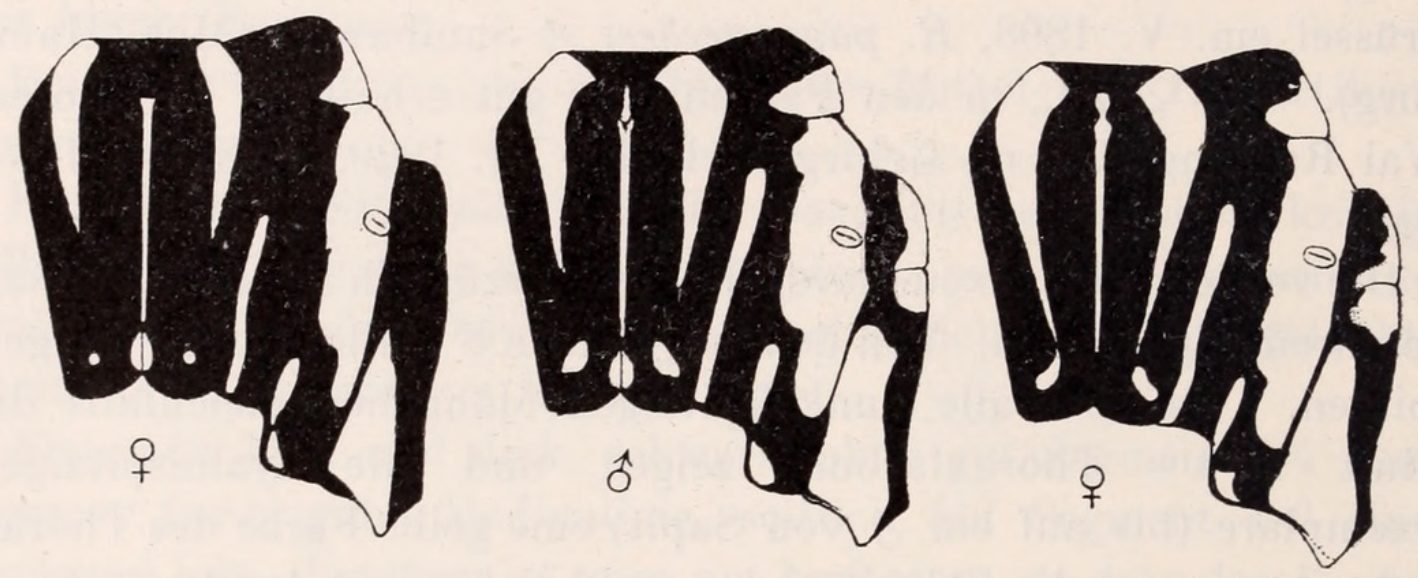

FIG. 3. - Rhinocypha pagen stecheri Först.

Links: Thoraxzeichnung eines $q R$. pag. pagenstecheri von Flores; rechts: Thoraxzeichnung des ô und $+R$. pag. timorana von Timor.

ein Strich entlang dem unteren Drittel des Hinterrandes, und ein grosser, kreisrunder Fleck auf der hinteren Hälfte der Oberseite.

Synthorax tiefschwarz und gelblichrot (s. Fig. 3). Fin breiter schwarzer Saum entlang der ganzen Seitenkante, von den Mittelcoxen bis zum 1. Abdominalsegment. Unterseite stark blau bereift, schwarz durchschimmernd, mit zwei breiten gelben Querbinden üher die vordere Hälfte und am Hinterrand mit einem Querstrich von der gleichen Farbe.

Coxen schwarz, innen blaubereift. Femora aussen schwarzbraun, innen gelb mit crême-weisslicher Bereifung; Tibien der Vorderbeine schwarzbraun, Aussenseite der Mittel- und Hintertibien gelbbraun, innen gelb mit starker crême-weisser Bereifung; Tarsen und alle Dornen schwarz. 
Flügel hyalin. Spitzen der Vorderflügel etwa 4-5 mm tief braunschwarz, Innenseite scharf begrenzt, leicht bogenförmig; Spitzen der Hinterflügel etwa 6-6,5 $\mathrm{mm}$ und weniger scharf abgesetzt gefärbt, die distalen Zweidrittel dieses Flecks mit lebhaft stahlblauem Reflex.

Abdomen schlank. Segment 1 rotgelb, oben an der Basis mit schmalem, rechteckigem schwarzem Fleck; Seiten breit schwarz gesäumt. Segment 2-8 lichtrot; 2-6 knapp vor dem Ende, je mit undeutlichem schwärzlichem Doppelpunkt. Segment 2 auch an der Basis oben mit nach hinten in feinste Spitze ausgezogenem dunklen Fleck. Segment 9-10 und Appendices tiefschwarz, die Intersegmentalmembran gelbrot. Genitalanhänge des 2. Segments schwarz. Sternite rot, von Segment 9-10 schwarz.

q (ad.). -- Oberlippe violettschwarz, mit querem, gelbem Mittelfleck. Mandibelbasis, Wangen und ein Seitenpunkt des Clypeus zusammenhängend hellgelb; diese Färbung entlang dem Augenrand, bis auf die Höhe des hinteren Ocellus, schmal nach oben fortgesetzt und dort abbrechend.

Lichte Farbe des Pro- und Synthorax dem ô sehr ähnlich, schmutzig fleischfarben anstatt gelbrot (Fig. 3 rechts).

Coxae und Trochanteren schwarz, gelb gefleckt. Vorderbeine schwarz, an der Basis schmal gelb. Mittel- und Hintertibien aussen schwarzbraun, innen gelb; Tarsen schwarz.

Flügel hyalin, Membran schmutzig grau. Pterostigma schwarzbraun.

Abdomen kurz und dick. Färbung schmutzig rotbraun, seitlich etwas aufgehellt. Segment 1 oben schwarz, an den Seiten gelb, mit schwärzlicher Umrahmung. Oberseite von 2 bis 6 je mit nach hinten allmählich grösser werdendem, scharf begrenztem, schwarzem Doppelfleck gegen das Ende der Segmente, jedes Paar durch eine feine gelbe Längslinie über die Mitte zweigeteilt und auch die schwarze Querlinien vor den Artikulationen oben durch die Medianlinie fein unterbrochen. Auf Segment 7 ist der schwarze Doppelfleck so sehr veryrössert, dass er die ganze Oberseite einnimmt und mit einem Seitenpunkte schmal zusammenhängt. Segmente 8-10 ganz schwarz, bis auf einen gelben Punkt jenseits der Mitte und eine gelbe Linie entlang der Unterseite des Tergits; 10. und Appendices ganz schwarz. Valven ebenso, geformt wie bei $R$. sumbana. Sternite schwarz. 
ô Abil. $18+1$ bis $19+1$; Hfl. 24-25,5 mm. o 17, $25 \mathrm{~mm}$.

Das ô unterscheidet sich von der typischen Rasse, ausser durch geringere Grösse und das schwarze 9. Segment, durch die Reduktion des schwarzen Spitzenflecks der Flügel, die violettmetallische Stirn, und die grösstenteils licht gefärbten Beine.

\section{Rhinocypha sumbana (Förster).}

(Fig. 4.)

1897. Förster, Ent. Nachr., 23, p. 335-336. — o Soemba R(. pagenstecheri Subrasse sumbana).

1898. Kr ÜGER, Stett. ent. Zeitg., 59, p. 133-135. - ơㅇ Soemba (R. braueri).

1916. Ris, Entom. Mitteilungen, 5, p. 317 (Tabelle), 318. - ô Soemba ( $R$. braueri).

M a t e ria l: 6 ô, 2 q (1 o juv.), E. Soemba, Kananggar,

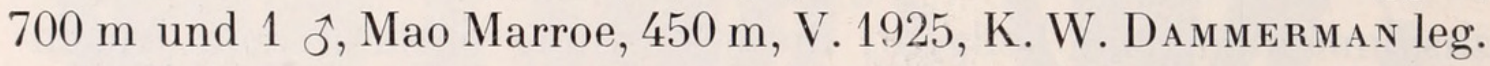

Nach dem vorliegenden, ausserordentlich schön in den Farben erhaltenen Material bin ich in erster Linie imstande, Förster's fragmentarische Beschreibung des seiner "Subrasse » zu vervollständigen, dann aber auch einige nomenklatorische Unklarheiten zu beseitigen.

Bis jetzt wurden zwei Arten unterschieden, pagenstecheri Först. und braueri Krüger, beide durch auffallende Grösse und durch lebhaft hellrote Färbung des Abdomens sehr ausgezeichnet und beide auf die Kleinen Sunda-Inseln beschränkt.

Die Ähnlichkeit von sumbana mit der echten pagenstecheri ist nur eine ganz oberflächliche, und die hauptsächlichen Unterschiede wurden bereits von Ris in seiner Tabelle erwähnt. Es war aber unrichtig, auf Grund einiger sicher fälschlich als von Soemba angegebenen Exemplare der pagenstecheri auch die Förstersche "Subrasse sumbana» als Synonym zu pagenstecheri zu stellen. Das von Ris unter pagenstecheri eingeordnete Material enthält nämlich 4 ô aus "Sumba », von denen ausdrücklich gesagt wird: "Sammler nicht genannt, Herkunft vielleicht unsicher ». Nehmen wir das letztere an und schalten wir obige $4 \hat{\sigma}$ ganz aus, dann erscheint das Vorkommen der pagenstecheri in Soemba als unbegründet und vorläufig als sehr zweifelhaft; ausserdem steht nichts mehr im Wege, die Förstersche sumbana wieder in ihre Rechte einzusetzen. Da nun $R$. braueri Krüger ein Jahr später als 
sumbana beschrieben wurde, muss letzterer Name für braueri eintreten.

KRÜGER's Beschreibung eines ô stimmt so vorzüglich auf unsere Exemplare, dass eine Neubeschreibung unterbleiben kann. Die Art ist in der Ausdehnung der Kopffärbung ein wenig variabel: die drei grossen, dicht zusammenstehenden, gelben Flecke zwischen Epistom (Clypeus) und Oberlippe einerseits und Auge anderseits sind nur beim einzigen juvenilen $\hat{o}$ deutlich vorhanden; bei allen anderen Exemplaren ist die ganze Vorderseite des Kopfes schwarz. Auch dieseitlichen Prothoraxflecke sind beim adulten $\widehat{o}$ bis auf winzige rötliche Punkte reduziert ; Vorderlappen und Lobus posterior tragen aber je eine grell gelbgefärbte Makel auf der Mitte. Bei gut ausgefärbten Exemplaren ist das Abdomen oben

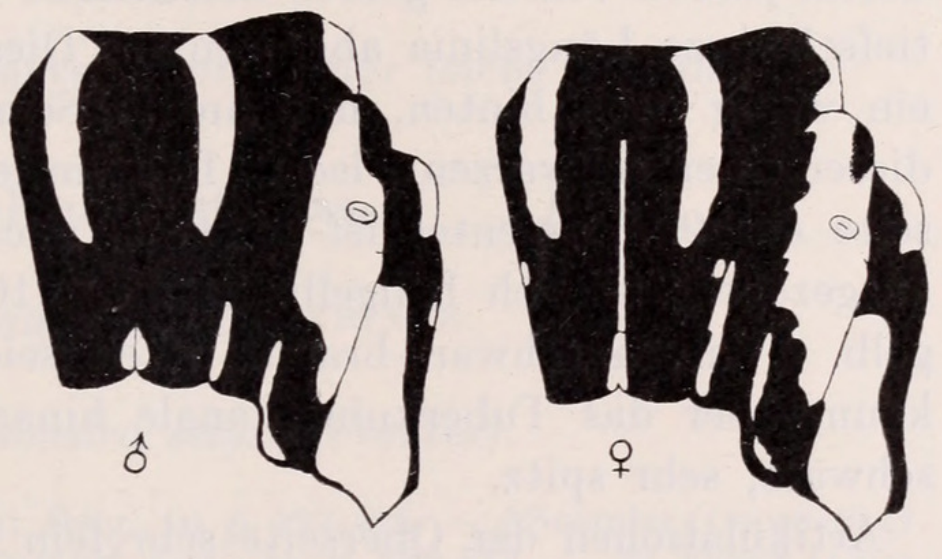

FIG. 4. - Rhinocypha sumbana Först., Soemba. Thoraxzeichnung. und seitlich völlig rot, ohne gelben Seitenstriemen an Segment 1-5, wie von KrüGER und Ris für unausgefärbte Stücke beschrieben wurde.

q: Die $q$ sind unter sich in der Färbung des Kopfes und des Abdomens ein wenig verschieden, was nur durch die Ausfärbung bedingt ist. Das jüngere Exemplar stimmt mit KrüGER's Notizen überein, das ältere, nahezu voll ausgefärbte $q$ liesse sich noch kurz beschreiben:

Oberlippe mit 2 ovalen gelben Flecken. Wangen und Mandibelbasis mit grossem, zusammenfliessendem Fleck von der gleichen Farbe. Clypeus und Oberseite des Kopfes tiefschwarz. Auf dem Vertex sind die 4 gelben Flecke sehr reduziert, punktförmig, die zwei Frontalflecke jedoch grösser, länglich-rechteckig, ungefähr ebensolang wie das gelbe 1. Antennenglied.

Prothorax oben wie beim $\hat{\jmath}$, überdies aber mit zwei grossen Seitenflecken und einem Strich oberhalb der Vordercoxen.

Synthorax hellgelb gefleckt, wie aus Figur 4 ersichtlich. Medianlinie deutlich gelb.

Rev. Suisse de Zool., T. 43, 1936. 
Aussenseite aller Femora dunkelbraun, Innenseite des 2. und 3. Paares schmutziggelb. Vordertibien ganz braun, Tibien des 2. und 3. Beinpaares bräunlichgelb. Tarsen schwarz.

Flügel wie beim $\hat{\jmath}$.

Abdomen kurz und dick. 1.-10. Segment mit in longitudinaler Richtung allmählich verschmälertem, hellgelben Seitenband, nahe dem Unterrand etwas ins rötliche ziehend und hinten zu einer ganz diffusen, rotbraunen Linie akzentuirt. Oberseite von Segment 1 an der Basis schmal schwarz. Segment 2-7 ganz rot, laterodorsal jedoch von der gelben Seitenfarbe durch eine gutbegrenzte, tiefschwarze Längslinie abgegrenzt. Diese Linie verbreitert sich ein wenig nach hinten, und am 8. Segment sieht man anstatt dieser einen schwarzen Fleck. Das vordere Dreiviertel der Oberseite des 9. Segmentes ist schwarz, nach hinten in eine Spitze ausgezogen; seitlich hellgelb. Segment 10 oben schwarz, seitlich gelb. Valven schwarz-braun, unten seicht gewölbt, die Spitze kaum über das Tuberkulum anale hinausreichend. Appendices schwarz, sehr spitz.

Artikulationen der Oberseite sehr fein bräunlich; Sternite aller Segmente schwarzbraun.

o Abd. 18,5 + 1. bis 20,5 + 1.; Hfl. 24-26 mm (Ris: 18,5, $23 \mathrm{~mm}$ ).

ㅇ 18-19, 27-28 mm (KrüGER: ô 19,5, 24; 우, $24 \mathrm{~mm}$ ).

\section{Libellago naias Lieftinck.}

1932. Lieftinck, Konowia, 11, p. 4-9 (Tabelle mit sumatrana). - ố West Flores und $\hat{\sigma} \mathrm{N}$. W. Soemba.

Diese Art wurde loc. cit. ausführlich beschrieben. Kein neues Material.

\section{Fam. Lestidae.}

\section{Lestes concinnus Selys.}

M a te ri a l: 1 ô ad., W. Soembawa, Soembawa-besar, XII. 1931, Ed. Handschin leg.

Gehört zu der ursprünglich von SELYs aus Batavia (West Java) beschriebenen, stark verdunkelten Form amata, die sich durch 
olivbraune oder düster blaugrüne Färbung des Thorax und der Seiten des Abdomen von Exemplaren jüngeren Alters unterscheidet. Es handelt sich hier nur um eine Ausfärbungsform, welche mit dem gelbbraunen Färbungstypus zusammen lebt. Das Pterostigma ist dunkel schwarzbraun, und die Flügel sind häufig gelbraun getrübt. Das vorliegende Exemplar ist von westjavanischen Stücken nicht zu unterscheiden.

\section{Lestes praemorsus (?) Selys.}

(Fig. 1'́t.)

M a te ria l: Nur Larven, von Timor (siehe Anhang).

\section{Fam. Agrionidae.}

\section{Subfam. Protoneurinae.}

\section{Notoneura selysi (Förster).}

1896. Förster, Ann. Soc. ent. Belg., 40,p. 423-424. - ổ Soemba (Caconeura). 1913. Ris, Abh. Senckenb. Naturf. Ges., 34, p. 508-512. — đำ Timor (Caconeura).

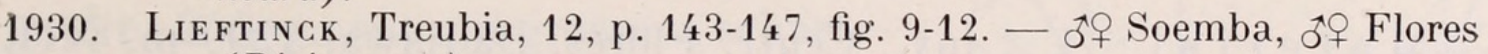
(Risioneura).

M a t e ri a l: 10 ठิ, 4 + , S. Timor, Koepang, Soë und Amarassi, XII. 1931-I. 1932, Ed. Handschin leg.

Im Gegensatz zu meinen früheren Ansichten (loc. cit.), dass die selysi von Timor vielleicht subspezifisch von der auf den Inseln Flores und Soemba lebenden Form verschieden sein könnte, glaube ich jetzt behaupten zu können, dass die am Ende meiner Beschreibung aufgezählten Unterschiede nicht genügend markiert und teilweise nicht ganz richtig angedeutet wurden, um eine isoliert stehende Rasse abzugrenzen. Die Serien von Flores und Soemba wurden nochmals nachgeprüft und mit den jetzt vorliegenden Exemplaren genau verglichen. Erwähnenswert ist in erster Linie, dass die - von Ris übernommene - Bemerkung in meiner Tabelle über die Färbung der Thoraxunterseite bei den Stücken von Flores und Soemba nicht ganz zutrifft. Das von mir zuerst beschriebene - allotypische - $q$ von Soemba hat eine ganz lichte Unterseite, während diese beim ô bisweilen völlig verdunkelt sein kann. Unter dem Material von Flores finde ich 
jetzt aber auch einige + mit schwarzer Ventralseite, sodass dieses Merkmal kaum zur Definierung von Inselrassen benutzt werden kann. Die ô Appendices sind bei Exemplaren von Flores und Soemba nicht greifbar verschieden; beim $\hat{\sigma}$ von Timor sind die unteren Appendices aber stets ein wenig kürzer. Die gelben Antehumeralstreifen sind bei allen $q$ von Timor länger als in meiner Tabelle erwähnt wurde und kaum merklich kürzer als beim typischen + von Soemba. Schliesslich finde ich nur einen ganz kleinen Unterschied in der Struktur des Prothorax der $q$ : beim $q$ von Timor ist der Lobus anterior in Dorsalansicht nicht schalenförmig ausgehöhlt, sondern mehr nach vorn aufgerichtet, sodass die Vertiefungen weniger deutlich sind.

Es bleiben also zwischen den Flores-Soemba Stücken und denjenigen von Timor nur einige geringe Differenzen in der Körpergrösse und der Ausbreitung der schwarzen Färbung am Thorax und Abdomen übrig.

\section{Notoneura emphyla sp. n.}

(Fig. 5 links und 6.)

M a t e ri a l: 1 ô juv., Centr. Flores, Badjawa, 1200 m, XII. 1931, Ed. Handschin leg.

Nahe N. selysi (Först.)

§.: Unterlippe nur an der Basis schmal weisslich. Kopf glänzend schwarz mit breiter, weit nach vorne gelegener, den Postclypeus
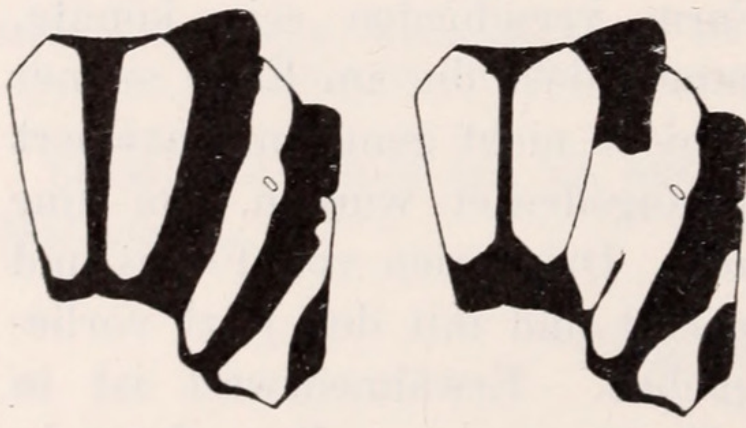

FIG. 5. - Notoneura emphyla sp. n., Flores. Thoraxzeichnung (links), und N. diadesma, sp. n., Soemba. Thoraxzeichnung (rechts).

Grundfarbe des Thorax oben licht bläulichweiss (juv!), seitlich
it grüner und gelber Beimischung; im adulten Zustande wahr-

Grundfarbe des Thorax oben licht bläulichweiss (juv!), seitlich
mit grüner und gelber Beimischung; im adulten Zustande wahrQuerbinde der Stirn. Vertex mit winzigem roten Punkt jenseits des lateralen Ocellus. Occiput schwarz.

Prothorax schwarz; jenseits der Mitte eine breite, kontinuirliche, bläulichweisse Längsbinde, die sich auf den Seiten des Lobus posterior fortsetzt. Letzterer einfach gerundet, kaum aufgerichtet. mit umfassender, weissgelber 
scheinlich leuchtend scharlachrot mit tiefschwarzer Zeichnung (Fig. 5). Hinterrand des Metepimerum ziemlich breit schwarz gesäumt. Ventralseite licht gefärbt.

Coxen braun; Aussenseite der Femora und Tibien schwarzbraun, Beine übrigens bräunlichgelb. Klauen, wie bei selysi, gezähnt.

Flügel verhältnismässig länger ausgezogen als bei selysi, Spitzen weniger abrupt gerundet, schmal elliptisch. Nervatur ähnlich selysi; das Rudiment von $C u_{1}$ erreicht den Flügelrand in der Mitte der ersten posttetragonalen Querader (Vorderfl.), oder reicht etwas über die Subnodalqueraderreihe hinaus (Hinterfl.). Distale Seite des $q$ analwärts durch eine Querader bis zum Rande verlängert. 16 Pnq im Vorderflügel, 14 im Hinterflügel. Pterostigma länger als bei selysi, proximale Seite viel kürzer als die distale und zweimal länger als die anale Seite, lichtbraun mit gelbem Randsaum.

Abdomen schwarz; 1. Segment schwarzbraun mit blauweissem Seitenpunkt. 2. Segment mit grossem, scharfbegrenztem, lichtblauem Dorsalfleck, vorn breit gegen den Vorderrand anschliessend, hinter der Mitte allmählich verschmälert und nur ganz schmal bis zum Hinterrand reichend; Seiten

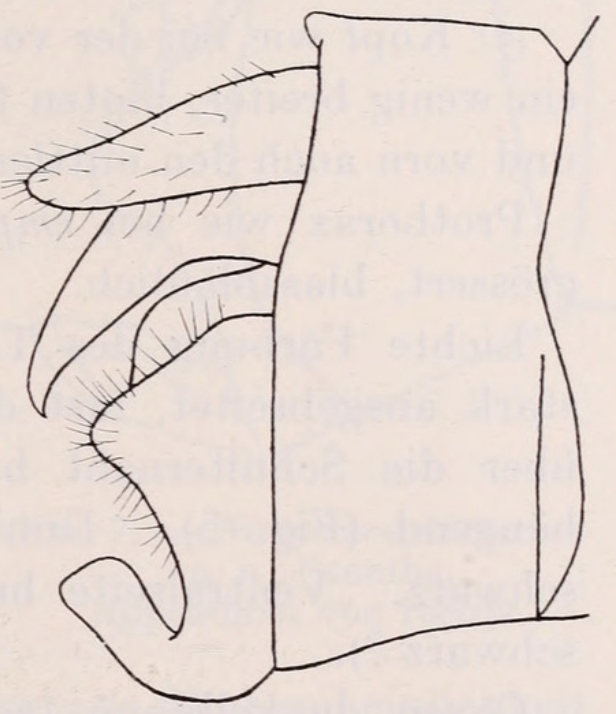

FIG. 6. - Notoneura emphyla sp. n., Flores.

Appendices von rechts. schwarzbraun mit schmutzig gelbbraunen Streifen entlang dem Unterrand. Dorsum des 3. Segments mit kleinem hellblauem Basisfleck, sonst schwarz. Segment 4-7 ganz schwarz, Seiten vor dem Ende jedes Segments etwas aufgehellt. Segment 8-10 seitlich schwarz, oben ganz lichtblau (juv.!); diese Färbung seitlich nicht übergreifend, nur die ganze Dorsalfläche einnehmend und nahezu parallelrandig.

Appendices schwarz, vom Typus der selysi. App. sup. in der Dorsalansicht dreieckig, mit starkem, schief nach unten gerichtetem, sehr spitzem innerem Zahn. App. inf. von der gleichen Länge und mit nach oben umgebogener, gerade abgestutzter Spitze (Fig. 6).

Abd. + App. 33,5, Hfl. 21 mm. 
Diese neue Art sieht juvenilen Exemplaren der $N$. selysi recht ähnlich und gehört mit ihr und mit der unten beschriebenen $N$. diadesma in eine Gruppe, welche durch die eigenartige Struktur der ô Appendices und durch das zweifellos bei voller Ausfärbung aller Arten scharlachrote Färbungsbild sehr ausgezeichnet ist.

\section{Notoneura diadesma sp. n.}

(Fig. 5 rechts und 7t)

M a t e ri a l: 1َ̧ (juv.), E, Soemba, Kananggar, 700 m, V. 1925, K. W. Dammerman leg.

ऽ: Kopf wie bei der vorigen Art, nur die gelbweisse Stirnbinde ein wenig breiter, hinten fast bis zur Basis der Antennen reichend und vorn auch den mittlern Teil des Anteclypeus miteinbeziehend.

Prothorax wie bei emphyla, die Seitenflecken ein wenig vergrössert, blassbläulich.

Lichte Färbung des Thorax blass weisslichblau (juv.!), sehr stark ausgebreitet, fast die ganze Dorsalfläche einnehmend und über die Schulternaht breit mit den Seitenflecken zusammenhängend (Fig. 5). Dunkle Zeichnungen scharf begrenzt, tiefschwarz. Ventralseite bräunlich (adult vielleicht teilweise tiefschwarz ?).

Coxen dunkelbraun (adult wahrscheinlich tiefschwarz); Beine sonst lichtbraun. Femora mit undeutlicher Ringelzeichnung und Innenseite derselben bräunlichgelb. Klauen am Ende gezähnt.

Flügelform wie bei emphyla. Spitzen etwas deutlicher gerundet. Nervatur identisch mit der vorigen Art. $18 \mathrm{Pnq}$ im Vorderflügel, 16 im Hinterflügel. Pterostigma ungefähr von der Länge wie bei emphyla, jedoch etwas schiefer gestellt und nach aussen nicht verbreitert: die proximale Seite ist ebensolang wie die distale und nicht ganz zweimal so lang als die anale Seite; blassbraun mit weisslichem Saum.

Abdomen schwarz, sehr ähnlich emphyla, aber das 1. Segment mit kaum sichtbarem hellen Seitenpunkt. Der juvenil blassblaue Fleck auf dem Dorsum des 2. Segments schliesst sich wie bei emphyla über die ganze Breite eng dem Vorderrand an und nimmt vorn die ganze Fläche ein; nach hinten wird er allmählich schmäler, bis knapp vor den Hinterrande, wo er plötzlich eingeschnürt erscheint und dort in einem kleinen medianen Spitzchen endet; 
der helle Saum am Unterrande dieses Segments ist schmal und nur vorne eben angedeutet. An der Basis des 3. Segments wie bei emphyla ein kleiner hellblauer Dorsalfleck, sonst ganz dunkel. Segment 4-7 ebenso, ohne deutliche Aufhellungen. Oberseite des 8.-10. Segments, mit Einschluss der Intersegmentalmembran, ganz lichtblau (juv!); diese Färbung seitlich nicht übergreifend, parallelrandig.

Appendices bräunlich verdunkelt, Oberseite der App. sup. gelb,in der Form sehr ähnlich emphyla, der innere Zahn der sup. jedoch ein wenig kürzer, und das Ende der inf. länger und mehr nach hinten gerichtet (Fig. 7).

Abd. + App. 35,5, Hfl. 23 mm.

Diese, leider nur in einem einzigen ô vorliegende Art ist von allen übrigen Arten der insignis-Gruppe dadurch verschieden, dass die mesepisternale helle Zeichnung des Thorax mit einer gleichgefärbten mesepimeralen breit verbunden ist. Wie bei der vorigen

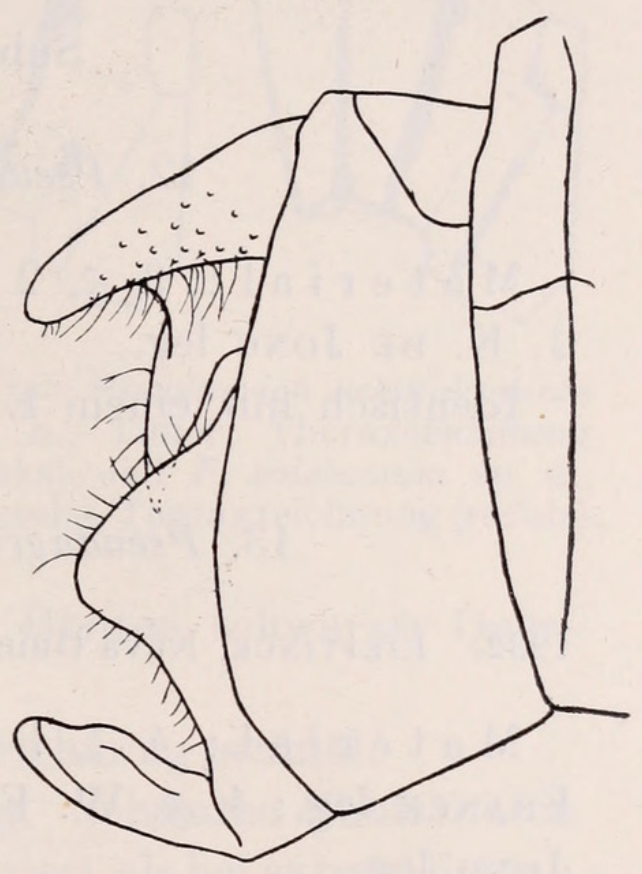

FIg. 7. - Notoneura diadesma sp. n., Soemba. Appendices von rechts. Art, dürfen wir mit einem grossen Mass von Wahrscheinlichkeit annehmen, dass auch die helle Thoraxzeichnung der diadesma im erwachsenen Stadium eine lebhaft scharlachrote Färbung aufweist.

Von dieser Gruppe kennen wir jetzt folgende Arten:

$N$. diadesma, sp. n., Soemba.

N. emphyla, sp. n., Flores.

$N$. insignis (Selys) (= fruhstorferi Krüger), Sumatra, Java.

N. selysi (Förster), Flores, Soemba, Timor.

Subfam. Platycneminae.

\section{Copera marginipes (Ramb.).}

M a t e r i a 1: 4 ô, 4 ㅇ, W. Flores, Mboera, 35 m, X. 1929, und Laboean Badjo, 100 m, XI. 1929, J. K. DE Jong leg.; 6今人, 2 ㅇ, N. E. Soemba, Kambera, III. 1925, und idem, Laora, $100 \mathrm{~m}$, IV. 1925, K. W. Dammerman leg. 
Das $\hat{\sigma}$ ist von javanischen marginipes nur dadurch verschieden, dass das distale Drittel des 8. Abdominalsegmentes oberseits auch licht gefärbt ist, während dort alle lichten Zeichnungen fehlen.

\section{Subfam. Agrioninae.}

\section{Pseudagrion rubriceps Selys.}

M a te rial: 3 ô, 2 q, W. Flores, Mboera, 35 m, X. 1929, J. K. DE JONG leg.

Identisch mit einem Exemplar von Java.

\section{Pseudagrion microcephalum (Ramb.).}

1932. Lieftinck, Nova Guinea, 15, Zool. 5, p. 92. - ợ Bali, Flores.

M a t e ri a 1: 4 jै, 1 †, E. Bali, Karangasem, X. 1928, P. F. Franck leg.; 1 ơ, W. Flores, Mboera, 35 m, X. 1929, J. K. de JoNG leg.

Die Exemplare von Bali sind die grössten, die ich je gesehen habe. Die schwarze Thoraxzeichnung ist etwas weniger entwickelt als bei javanischen Stücken, das 8. Abd.-Segment trägt am Ende aber einen schmalen, schwarzen Ring, der auch beim $\hat{o}$ von Flores vorhanden ist. Die Unterschiede sind sonst minimal und ohne Bedeutung.

Nach brieflicher Mitteilung von Miss C. Longfield, London, fand sie auf ihren Reisen durch den Archipel auch 2 o dieser Art auf Bali (5. XII. 1929).

\section{Pseudagrion schmidtianum sp. n.}

(Fig. 8 und 9 links, 10.)

M a t e ri a l: $3 \hat{\jmath}$, S. Timor, Amarassi, XII. 1931-I. 1932, Ed. Handschin leg.

Sehr ähnlich microcephalum und verwandten Arten, aber verschieden durch die reduzierte Schwarzfärbung an Kopf und Thorax, und durch die anders gestalteten Appendices anales.

$\widehat{\jmath}$ : Kopf grösser und breiter als bei microcephalum; ganze Vorderseite desselben hell grünlichblau, anstatt tiefblau wie bei der 
Vergleichsart. Ausdehnung der oberen schwarzen Querbinde zwischen den Augen etwas variabel, durchschnittlich schmäler als bei microcephalum, vorn zackig begrenzt und den vorderen Ocellus freilassend; seitlich entweder dem Augenrand breit angesetzt (Typus und 1 Paratypus), oder schmal durch blau getrennt. Postocularflecke entweder sehr zackig, aber mit dem hellen Occipitalstreif verbunden (Paratypen), oder vollständig (seitlich durch eine schmale Linie entlang dem
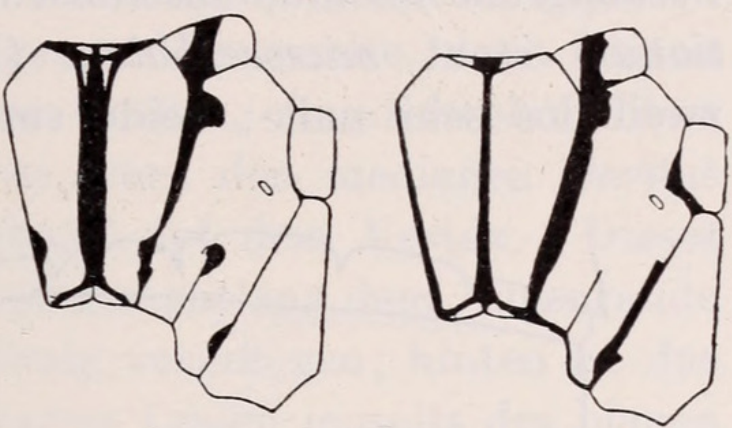

Fig. 8. - Pseudagrion schmidtianum sp. n., Timor, Thoraxzeichnung (links), und P. calosomum sp. n., Soemba, Thoraxzeichnung (rechts).

Augenrand) schwarz umrahmt (Typus). Breiter, schwarzer Querstrich am Occiput.

Prothorax grünlichblau, die Schwarzzeichnung schmal.

Synthorax hellblau mit grünem Anflug. Schwarze Nahtstreifen noch mehr reduziert als bei extrem lichten Exemplaren von microcephalum; die Median- und Schulterlinien schmal, bei den
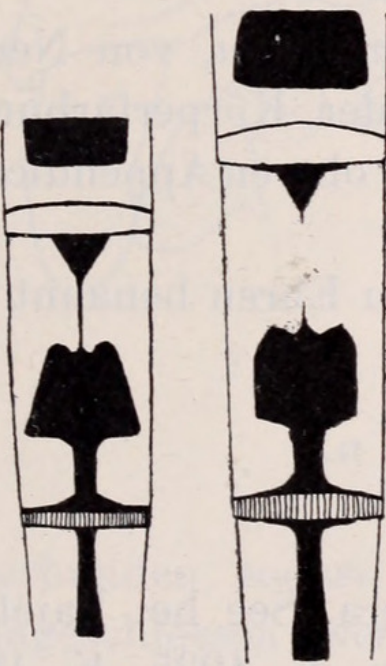

FIG. 9. - Pseudagrion schmidtianum, sp. n., Timor, Segm. 1-2 des Abdomen (links), und P. calosomum, sp. n., Soemba, Segm. 1-2 des Abdomen (rechts). Paratypen noch ein wenig schmäler als beim Typus. (Fig. 8)

Färbung des Abdomens sehr ähnlich microcephalum, aber alle dunklen Zeichnungen auf Segment 3-6 schmäler. Zeichnung von Abd.-Segment 1-2 bei den vorliegenden Exemplaren nicht variabel (Fig. 9). Segment 8-10 blau, schwarze Zeichnung auf der Oberseite von 10 wie aus der Figur der Appendices ersichtlich. Abdomen, vom Anfang des 8. Segmentes ab, nach hinten allmählich aber stark seitlich erweitert.

Appendices ganz schwarz. App. sup. deutlich kürzer als Segment 10, stark divergierend, ohne jegliche Spur eines Basalzahnes, nahe der Mitte der Innenseite mit winzigem Zahnspitzchen oberhalb des Unterrandes (Fig. 10). 
Abd. + App. 27-28,5, Hfl. 18-19 mm.

Diese neue Art wurde mit allen mir bekannt gewordenen blauen Pseudagrion der indo-australischen Region verglichen. P. schmidtianum steht microcephalum (Ramb.) und pelecotomum Lieft. zweifellos sehr nahe; beide sind aber durch die Struktur ihrer

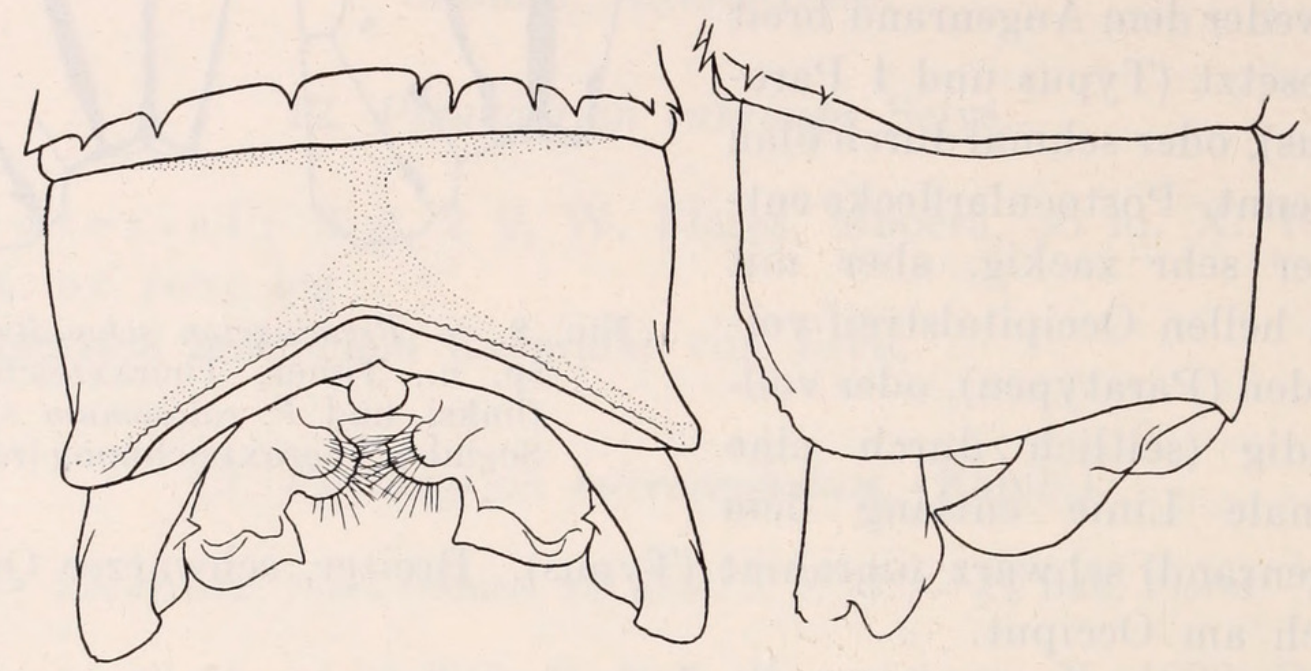

FIG. 10. - Pseudagrion schmidtianum sp. n., Timor. Appendices, dorsal und von rechts.

Appendices leicht $\mathrm{zu}$ unterscheiden. Mit pelecotomum, von NeuGuinea, besteht eine gewisse Aehnlichkeit in der Körperfärbung und in der Form der App. inf.; der untere Ast der oberen Appendices ist bei dieser Art aber viel stärker erweitert.

Herrn Dr. Erich Schмпт in Berlin-Steglitz zu Ehren benannt ${ }^{1}$.

\section{Pseudagrion calosomum sp. $\mathrm{n}$.}

(Fig. 8 und 9 rechts, 11.)

Mate ri a l: $5 \hat{\jmath}$, N. E. Soemba, Kambera, See bei Pajeti, III. 1925, und E. Soemba, Kananggar, 700 m, V. 1925, K. W. Dammerman leg.

1 Neuerdings erhielt ich aus Djokjakarta (Zentraljava) eine Serie einer blauen Pseudagrion, die in allen Einzelheiten mit meiner P. nigrofasciatum aus Ostjava (Stylops, 3, 1934, p. 6-8) und mit P. infracavum Schmidt aus Ostjava (Arch. Hydrob., Suppl.-Bd. XIII, 1934, p. 349-350) übereinstimmt. Die Beschreibung der erstgenannten wurde, wie sich bei der Nachprüfung des Materiales herausstellte, leider nach stark verfärbten Exemplaren aufgestellt; um das Mass voll zu machen, wurde ausserdem auch der von ScнміDт für infracasum richtig erwähnte, ganz kleine Basalzahn der App. sup. übersehen, sodass Scнмір veranlasst wurde, eine neue Art aufzustellen. P. infracasum ist aber sicher mit nigrofasciatum identisch. 
Grosse und robuste Art; Körperfärbung vom reinsten grünlichblau (Lumière-blue nach Ridgway).

§: Kopf nicht besonders gross. Färbung bei allen Exemplaren fast gleich: Unterlippe gelblich; ganze Vorderseite, nach hinten bis zu dem Niveau des vorderen Ocellus, Lumière-blau, ohne schwarze Punkte. Ziemlich breites, vorn den medianen Ocellus fast berührendes, schwarzes Querband auf dem Vertex. Dieses Band ist vorn nahezu geradlinig und nur entlang dem Augenrande auf eine ganz kurze Strecke ein wenig vorgezogen; hinten ist das Band mittels zweier schräger schwarzer Linien jenseits des blauen Querstrichs am Occipitalrand mit dem Schwarz des Occiputs

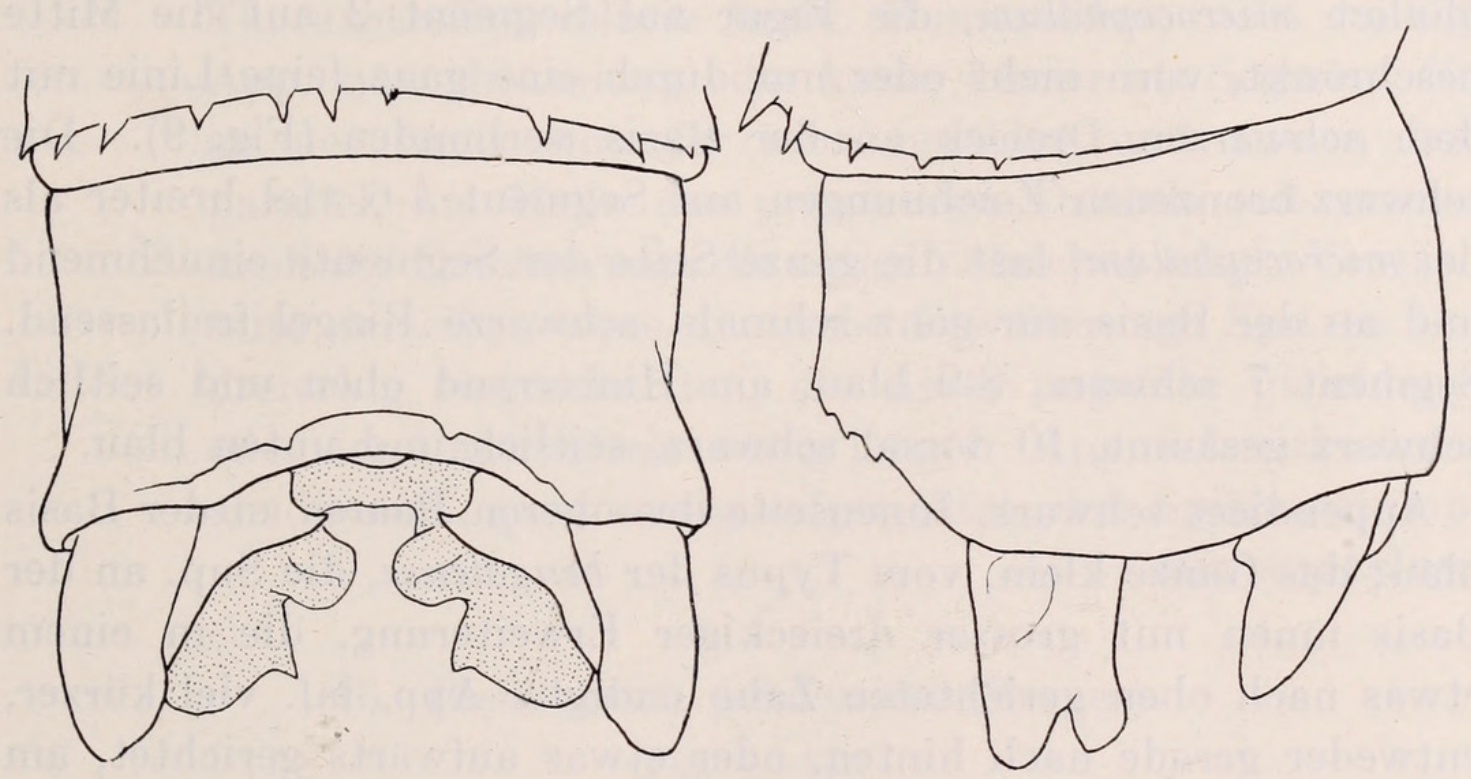

FIG. 11. - Pseudagrion calosomum sp. n., Soemba.

Appendices, dorsal und von rechts.

verbunden, sodass zwei stark vergrösserte, blaue Postocularflecke eingeschlossen werden, die auch am Augenrand schmal durch schwarz begrenzt sind.

Prothorax blau, seitlich breit schwarz gesäumt und oben mit eịner kontinuirlichen M-förmigen Figur auf der Mitte; Hinterrand blau.

Synthorax oben und seitlich gleichmässig rein Lumière-blau; schwarze Zeichnung sehr reduziert: äusserst feine Linie der Mittel naht; vollständiger gerader Strich über die Schulternaht, unten auf den Schulterbeulen etwas erweitert und quer über das Mesinfraepisternum ziehend; schmale, aber scharf ausgeprägte Linie 
entlang der hinteren Seitennaht, unten vor dem Stigma plötzlich abbrechend und längs dem Metinfraepisternum wieder schmal fortgesetzt; kein schwarzer Punkt an der ersten Seitennaht. Ventralseite lichter (Etain-blue nach RIDGWAY), dünn weisslich bereift (Fig. 8).

Beine grünlichblau; Aussenseite der Femora und Innenseite der Tibien schwarz; Tarsen schwarz, Klauen rötlich.

Flügel hyalin; 10-11 Pnq im Vorderflügel, 9 im Hinterflügel. Pterostigma dunkel rotbraun, lang-rhombisch, Innen- und Aussenecken sehr spitz.

Färbung des Abdomens grünlichblau; 1. bis 3. Segment sehr ähnlich microcephalum, die Figur auf Segment 2 auf die Mitte beschränkt, vorn nicht oder nur durch eine ganz feine Linie mit dem schwarzen Dreieck an der Basis verbunden (Fig. 9). Die schwarz-bronzenen Zeichnungen auf Segment 4-6 viel breiter als bei microcephalum, fast die ganze Seite der Segmente einnehmend und an der Basis nur ganz schmale, schwarze Ringel freilassend. Segment 7 schwarz, 8-9 blau, am Hinterrand oben und seitlich schwarz gesäumt, 10 dorsal schwarz, seitlich und unten blau.

Appendices schwarz, Innenseite des oberen Paares an der Basis blau; das Ganze klein, vom Typus der bengalense, die Sup. an der Basis innen mit grosser dreieckiger Erweiterung, die in einem etwas nach oben gerichteten Zahn endigt. App. inf. viel kürzer, entweder gerade nach hinten, oder etwas aufwärts gerichtet, am Ende stumpf (Fig. 11).

Abd. + App. 34-36,5, Hfl. 22,5-24 mm.

Diese schöne neue Art ist einer der grössten Vertreter seiner Gruppe; sie scheint mit $P$. bengalense am nächsten verwandt $\mathrm{zu}$ sein.

Zur Erleichterung der Bestimmung wurde folgende Tabelle der $\hat{\sigma}$ aufgestellt; die leicht kenntliche rubriceps wurde fortgelassen.

1. Sehr grosse Art: Abd. + App. 34-36,5, Hfl. 22,5-24 mm. Extreme Reduktion der schwarzen Thoraxzeichnung. Deutliche schwarze Linie der hinteren Seitennaht. Letzte Abd.-Segmente kaum erweitert. Appendices anales kürzer als Segment 10 . . . . . . calosomum.

1'. Kleinere Arten: Abd. + App. bis 30, Hfl. bis 20 mm. Keine schwarze Linie der hinteren Seitennaht. 
2. Letzte Abd.-Segmente deutlich erweitert. Schwarze Thoraxzeichnung reduziert, Humerallinie sehr zackig. App. sup. kürzer als Segment 10, sehr breit getrennt und divergierend, an der Basis innen ohne Zahn; Ventralseite derselben mit kleiner Ausbuchtung; Spitzen kurz dreieckig eingeschnitten, die Aeste ungefähr gleichlang. App. inf. in der Seitenansicht mit spitzem, schräg messerförmig nach oben gerichtetem Aussenast, die Spitzen der sup. nicht erreichend, aber mindestens ebensolang wie diese schmidtianum.

2'. Letzte Abd.-Segmente kaum merklich erweitert. Schwarze Thoraxstreifen relativ breit, Humerallinie nicht zackig. App. sup. ebensolang oder kaum kürzer als Segment 10, an der Basis einander sehr genähert und aussen fast parallel, am Ende des proximalen Drittels mit grosser medialer Erweiterung, die einige Zähnchen trägt; Ventralseite derselben ohne deutliche Erweiterung; Spitzen tief dreieckig eingeschnitten, die Aeste ungefähr gleichlang, oder der Unterast ein wenig länger. App. inf. viel kürzer als die sup., ganz wenig aufgerichtet, ihre Spitzen stumpf microcephalum.

16. Pseudagrion pilidorsum (Brauer).

(Fig. 12-13.)

Diese weitverbreitete Art soll an dieser Stelle etwas eingehender betrachtet werden, ganz besonders darum, weil sie in den vorliegenden Sammlungen der Kleinen Sunda-Inseln reichlich vertreten ist, und ferner, weil mir jetzt auch eine schöne Serie der typischen Localität (Philippinen) vorliegt.

Gelegentlich einer Bearbeitung der Odonaten von Simaloer, einer Insel westlich von Sumatra, hat Ris schon bemerkt, "dass pilidorsum ein gewisses Mass von Polymorphismus zu zeigen scheint » (Tijdschr. Ent. 58, 1915). Später (Misc. Zool. Sum., LIX, 1931) habe ich darauf hingewiesen, dass es an der Hand eines reichlichen Materiales in Zukunft möglich sein würde, die Art in eine Anzahl wohl charakterisierte geographische Rassen aufzuteilen.

Da mir jetzt, wie gesagt, beträchtliche Serien von zum Teil weit auseinander liegenden Fundorten vorliegen, soll hier der Versuch 
gemacht werden, die verschiedenen geographischen Subspecies möglichst genau zu definieren. Die Differenzen sind erheblich und nicht nur auf die Färbung beschränkt; -sie haben sich als genügend konstant erwiesen, um die verschiedenen Rassen auch zu benennen, was sich ebenfalls an einer Menge anderer Odonatenspecies des Archipels durchführen liesse.

$P$. pilidorsum ist im männlichen Geschlecht von allen verwandten Arten der pruinosum-Gruppe verschieden durch die Gestalt der Appendices anales, durch die adult rostrote oder hell braunorange Färbung des Thorax, welchem oben jede Spur einer blauen Bereifung fehlt, durch die starke Reduktion der schwarzen Linien an den Thoraxnähten und durch die mindestens teilweise orange oder rostrote Färbung der basalen und terminalen Abdomensegmente. Unser Material gestattet folgende Rassengliederung:

1. Dorsum des Abdomens schwarzgrünbronze, auch auf den basalen Segmenten. Ganzer Vorderkopf von der Oberlippe bis zum vorderen Ocellus hell eitrongelb, hier ziemlich abrupt gegen die fast schwarze Ober- und Hinterseite des Kopfes abgegrenzt. Diffuse Andeutung winziger rostroter Postocularflecken; Occiput ganz schwarz, Augen nur seitlich ganz schmal gelb gerandet. Ganze Oberseite des Prothorax und der Mesepisterna fast bis zur Schulternaht schwarz verdunkelt, seitlich in dunkel weinrot übergehend. Ventralseite dünn weisslich bereift. Schenkel aussen und Tibien innen schwarz, Tarsen schwarz. Flügel stark gebräunt, Pterostigma lichtbraun. Segment 1-2 seitlich und unten rot. Basale Hälfte oder Zweidrittel des 9. Segments rot, 10 rot mit X-förmiger schwarzer Zeichnung. App. sup. länger und schlanker als bei $p$. pilidorsum, sup. in der Seitenansicht am Ende etwas unregelmässig begrenzt, nicht eingeschnitten; innen, etwas unter der dorsalen Kante, zwei kleine gerundete, schwarze Höckerchen, eins etwas distal von der Mitte, das andere am Ende (von oben nicht sichtbar); an der ventralen Kante ein ganz kleines Zähnchen ungefähr in der Mitte der Länge. App. inf. kaum halb so lang, wie in der Figur $12 b$. Länge: Ahd. + App. 37, Hfl. 24 mm Nias, ? Simaloer . . . . . . pilidorsum obscurum. 
1'. Dorsum des Abdomens, mindestens des 1. und 2. Segmentes, rostrot oder rot.

2. Basis des Abdomens, vom 1. bis 3. Segment rot oder rostbraun, 2-3 mit schmalem schwarzem Endring und 3 oben am Ende mit schwarzem Mittelfleck; seltener auch das vordere Dreiviertel oder Zweidrittel des 4. Segments rot, nach binten allmählich in schwarzbronze übergehend. Segment 4-8 oben schwarzgrünbronze, seitlich rotgelb, 4-6 mit winziger roter Basislinie. Basalhälfte oder vordere Zweidrittel des 9. Segments rot, Rest oben schwarz, die vordere Begrenzung etwas variabel; 10 rot mit $\mathrm{X}$-förmiger schwarzer Zeichnung. Kopf vorn und oben gleichmässig hell rostbraun bis braungelb; Postocularflecke meistens etwas verdunkelt, ringsum - auch längs dem Augenrande! - fein schwarz gesäumt. Thorax bis zur zweiten Seitennaht olivbraun, die Gegend der Schulternaht rostbraun; Mediannaht, obere Mesothoracal-Suturen unter den Flügeln und je ein kurzer, eingedrückter Strich oben an der Schulter- und 2. Seitennaht fein schwarz; Unterseite dünn weisslich bereift. App. sup. kurz und dick, von oben gesehen kaum so lang als Segment 10, in der Seitenansicht kürzer, am Ende ohne Einschnitt; innen, etwas unter der dorsalen Kante, zwei robuste schwarze Zähne, einer etwas distal von der Mitte, der andere nahe dem Ende; an der ventralen Kante ein ganz kleines Zähnchen etwas proximal vom ersten Drittel. App. inf. mehr als halb so lang, wie in der Figur 12 a. Länge: Abd. + App. 31-35, Hfl. 22-24 mm. - Philippinen, Formosa... pilidorsum pilidorsum.

2'. Basis des Abdomens vom 1. bis 2. Segment rostrot oder rot, 2. bisweilen noch mit kleinem kreuz- oder punktförmigem Dorsalfleck nahe dem Hinterrand, isoliert oder mit diesem verbunden. Ganzer Vorderkopf von der Oberlippe bis zur Mitte zwischen vorderen und hinteren Ocellen hell citron- oder orangegelb, hier gerade und ziemlich abrupt gegen die rostbraune Ober- und Hinterseite des Kopfes abgegrenzt. Postocularflecke meistens nur vorn und in der Mitte durch eine feine schwarze Linie vom Vertex und der mittleren Occipitalkante abgegrenzt, bisweilen 
auch am Occipitalrand diffus bräunlich gesäumt. Occiput nur ganz hinten und unten in der Mitte schwarz; Augen hinten breit gelb gesäumt. Prothorax oben nur in den Furchen ganz fein schwarz liniert. Thorax hell rostrot; schwarze Medianlinie kaum angedeutet; Humeral- und zweite Seitennaht nur ganz oben mit schwarzem eingedrücktem Strich. Unterseite grell weisslich bereift. Beine lichtbraun; Kniee der Vorder- und Mittelbeine nur innen an der Basis schwarz. Flügel hyalin. Segment 3-8 oben schwarzgrünbronze, 3 seitlich rot; 9-10 ganz rot, am Ende oben und seitlich mit schwarzem Saum.

3. Grösser. App. sup. lang und schlank, von oben gesehen länger als Segment 10, in der Seitenansicht gerade, Spitze oben vorspringend, hinten mit deutlichem gerundetemi Einschnitt, die Aeste ungleich; obere Begrenzung in der Seitenansicht leicht gewellt; Innenseite an der dorsalen Kante in der Mitte mit grossem, wenig vorspringendem, schwarzem Höcker und mit nach innen gerichtetem Endzahn; an der ventralen Kante ein kleines schwarzes Zähnchen etwas proximal vom ersten Drittel. App.inf. etwa halb so lang, wie in der Figur $13 a-b$. Länge: Abd. + App. 32-36, Hfl. 20-23 mm (Lombok, Soembawa, Flores, Soemba), 34-36,5, $23 \mathrm{~mm}$ (Soemba) . . pilidorsum declaratum.

3'. Durchschnittlich etwas kleiner und schlanker. Schwarze Linien am Hinterkopf obliteriert und Nahtstreifen am Thorax fast ganz fehlend. App. sup. ganz anders gestaltet: in der Seitenansicht kürzer und in der Mitte deutlich verbreitert, von oben gesehen etwas kürzer als Segment 10, in der Seitenansicht deutlich gekrümmt, Spitze verschmälert und ganz abgerundet, mit sehr kleinem Einschnitt; obere Begrenzung in der Seitenansicht gleichmässig convex; Innenseite an der dorsalen Kante distal von der Mitte mit spitz vorspringendem Zahn, aber ohne Endzahn; an der ventralen Kante ein deutliches Zähnchen etwas proximal vom ersten Drittel. App. inf. mehr als halb so lang, in der Seitenansicht fast spitz (Fig. 13c). Länge: App. + App. 30.5-35, Hfl. 19-22 mm. - Timor 
16. a) Pseudagrion pilidorsum obscurum subsp. n.

(Fig. 12 b.)

1931. Lieftinck, Misc. Zool. Sum., LiX, p. 4. - ô Nias (P. pilidorsum).

?1915. Ris, Tijdschr. Ent., 58, p. 12-13. - ô Simaloer (P. pilidorsum).

?1926. Laidlaw, Journ. Mal. Br. Roy. Asiatic Soc., 4, p. 219 (Sumatra, errore!), 231. - ô Sipora (P. pilidorsum).

M a te ri a l: 2 ô (adult, gut erhalten), Nias, Amadraja, 10. IX. 1931, J. C. van der Meer Mohr leg.

Diese Rasse ist in der Tabelle genügend charakterisiert. Weibchen liegen nicht vor. Die von Ris erwähnten zwei $\hat{\jmath}$ von der Insel

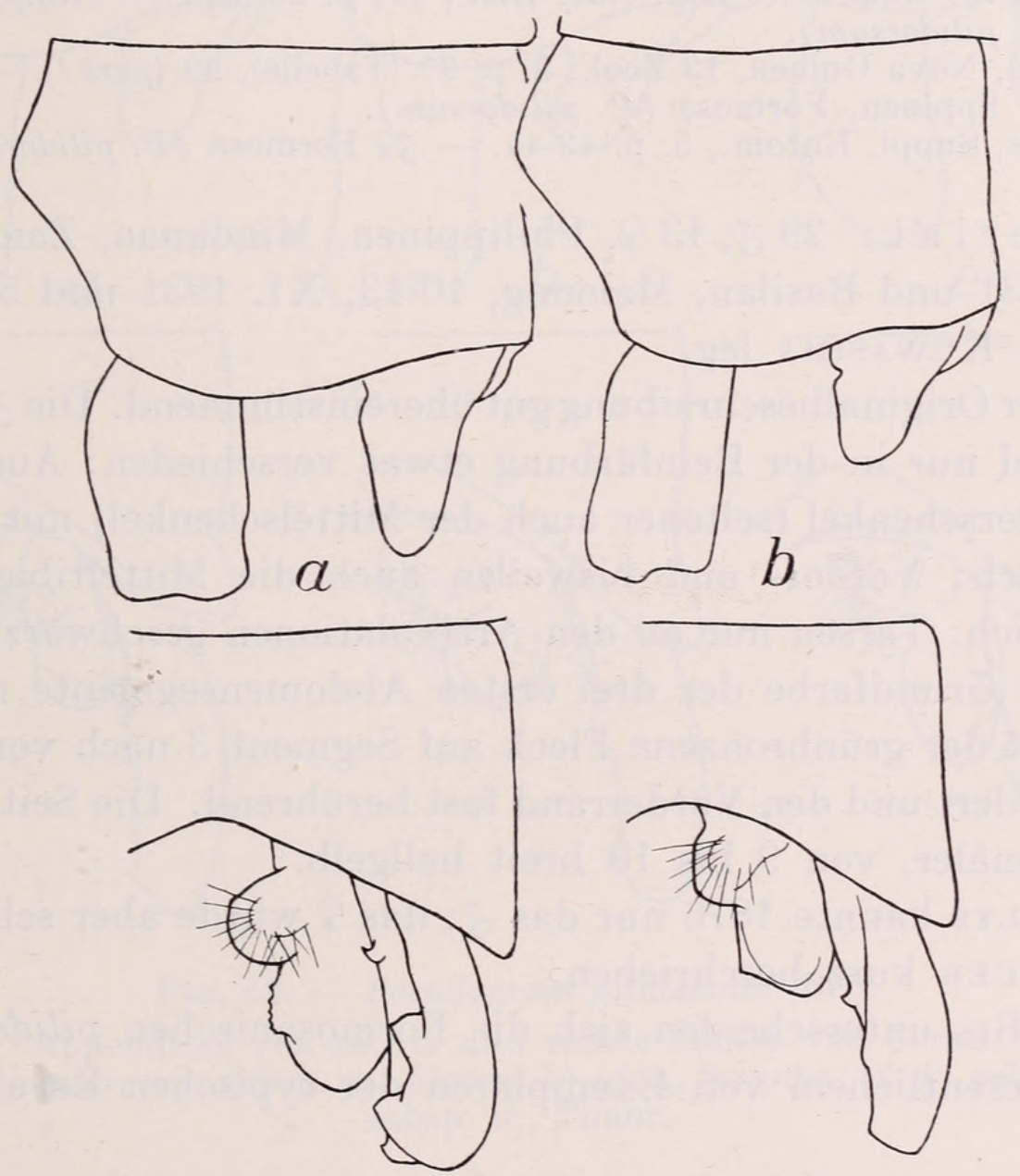

FIG. 12. - Pseudagrion pilidorsum (Br.).

Appendices von rechts und rechte Hälfte von dorsal.

a) P. pil. pilidorsum, Philippinen; b) P. pil. obscurum subsp. n., Nias.

Simaloer gehören vielleicht auch hierher, obwohl sie nach der Beschreibung nicht die extrem verdunkelte Oberseite des Kopfes und Thorax zeigen. Über die Struktur der Appendices liegen

Rev. Suisse de Zool., T. 43, 1936. 
keine Angaben vor. Auch von den Mentawei-Inseln (Sipora) wurde pilidorsum angegeben; leider hat Laidlaw keine Beschreibung zu diesen Exemplaren gegeben.

Es wäre sehr gut möglich, dass es sich hier um eine eigene Inselrasse handelt, deren Nachprüfung sehr wünschenswert erscheint.

\section{6. b) Pseudagrion pilidorsum pilidorsum (Brauer).}

(Fig. 12 a.)

1868. Brauer, Zool. bot. Ges. Wien, 18, p. 553-554. - ợ Luzon, Minanao (Agrion pilidorsum).

1876. Selys, Synops. Agrion (Suite), p. 224-225. - ô Luzon (P. pilidorsum). 1882. Selys, Anal. Soc. Esp. Nat. Hist., 11, p. 28 sep. - Philippinen ( $P$. pilidorsum).

1915. Ris, Nova Guinea, 13 Zool., 2, p. 97 (Tabelle), 99 (pars!). — đơ Philippinen, Formosa ( $P$. pilidorsum).

1916. Ris, Suppl. Entom., 5, p. 43-44. - ơ Formosa (P. pilidorsum).

M a t e r i a 1: 29 今ે, 13 \&, Philippinen, Mindanao, Zamboanga, VIII. 1931 und Basilan, Maloong, 10-13. XI. 1931 und 5-14. IX. 1932, K. Kuwasima leg.

Mit der Originalbeschreibung gut übereinstimmend. Die ồ unserer Serie sind nur in der Beinfärbung etwas verschieden: Aussenseite der Vorderschenkel (seltener auch der Mittelschenkel) mit schwarzem Strich; Vorder- und bisweilen auch die Mitteltibien innen schwärzlich; Tarsen nur an den Artikulationen geschwärzt. Beim + ist die Grundfarbe der drei ersten Abdomensegmente rot; bisweilen ist der grünbronzene Fleck auf Segment 3 nach vorn kaum verschmälert und den Vorderrand fast berührend. Die Seiten von 8 sind schmäler, von 9 bis 10 breit hellgelb.

De Selys kannte 1876 nur das ô; das q wurde aber schon 1868 von Brauer kurz beschrieben.

Nach Ris unterscheiden sich die Formosanischen pilidorsum in nichts wesentlichem von Exemplaren der typischen Localität.

16. c) Pesudagrion pilidorsum declaratum subsp. $\mathrm{n}$.

(Fig. $13 a-b$.)

1915. Ris, Nova Guinea, 13 Zool., 2, p. 97 (Tabelle), 99 (pars!), Fig. 20 (Apps.). - ô Flores (P. pilidorsum).

M a t e ri a l: 1 ô, 2 o , E. Lombok, Sapit, 600 m, IV. 1896, H. Fruhstorfer leg. (Mus. Hamburg). $-1 \hat{\jmath}$, W. Soembatva, 
Soembawa-besar, XII. 1931, Ed. Handschin leg. - 22 §, 6 q, W. Flores, Mboera, $35 \mathrm{~m}$, Laboean Badjo, $100 \mathrm{~m}$, Wai Radjang, 140 m, Naga, 220 m, X.-XI. 1929, J. K. de Jong leg.; 3 o, 2 , Flores, Todabeloe, 500 m, und Badjawa, 1200 m, XII. 1931, Ed. Handschin leg.; 1 $\hat{\delta}$, N. Flores, Rioeng Papang, Alo Wai Fluss,

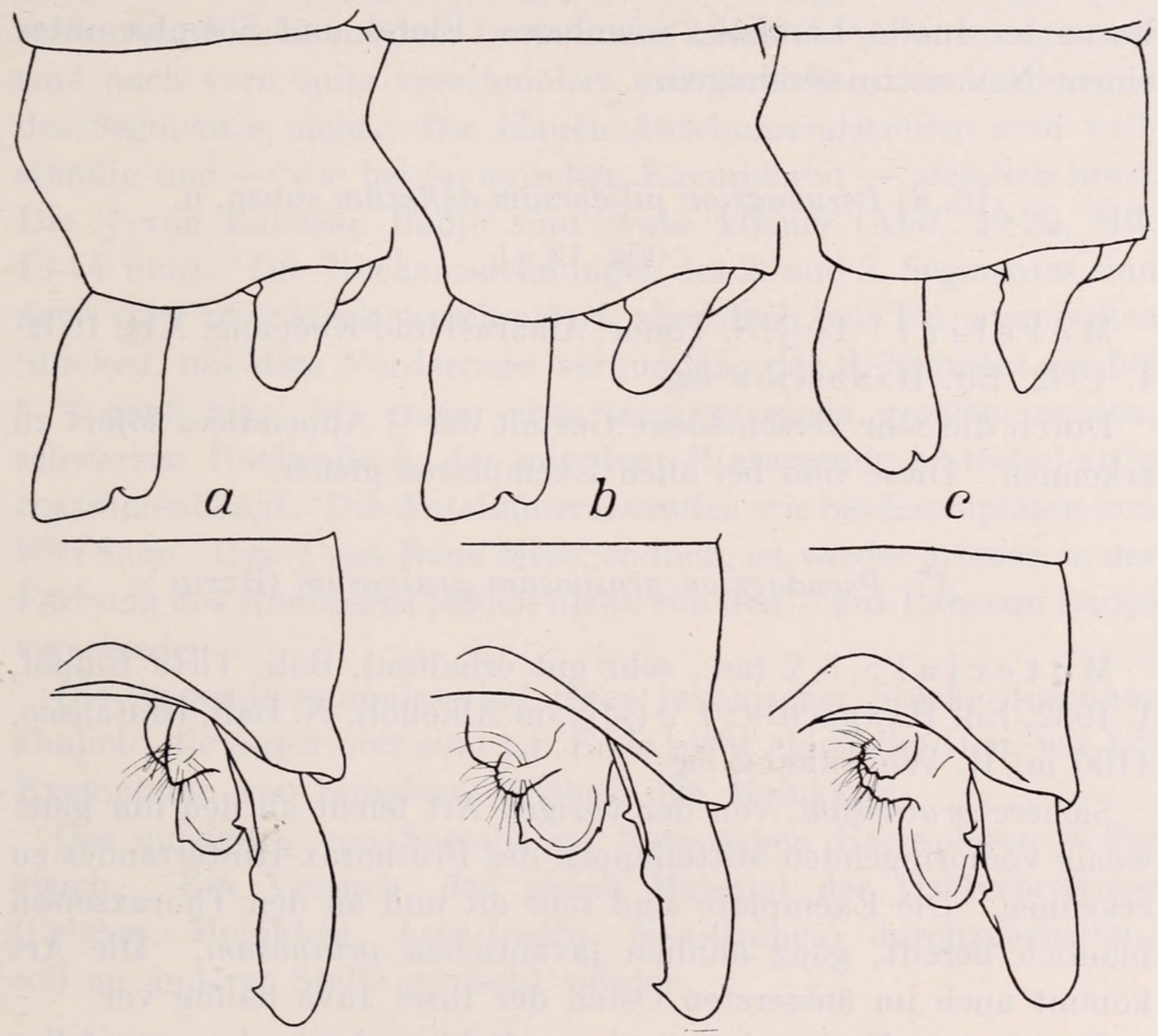

FIG. 13. - Pseudagrion pilidorsum (Br.).

Appendices von rechts und rechte Hälfte von dorsal.

a) P. pil. declaratum subsp. n., Flores; b) idem, Soemba; c) P. pil. deflexum subsp. n., Timor.

28. IX. 1908, van der Sande leg. - 8 ^ै, 6 ?, N. E. Soemba, Kambera, III. 1925 und E. Soemba, Kananggar, 700 m, V. 1925, K. W. Dammerman leg.

Die Hauptcharaktere dieser Subspecies sind aus vorstehender Tabelle ersichtlich. Die Exemplare von Lombok und Flores sind nahezu identisch, das einzige ô von Soembawa ist etwas juvenil, 
aber in der Form der Appendices nicht von floresischen Stücken verschieden. Endlich sind die $\hat{o}$ von der Insel Soemba etwas robuster; ihre Appendices sind eine Spur dicker und ganz wenig mehr abgerundet. Alle Weibchen sind, ausser durch düstere Färbung, durch die diffuse Verdunkelung der Oberseite des 2. Abdominalsegments ausgezeichnet. Ich glaube am Besten zu tun, die Form der Inseln Lombok, Soembawa, Flores und Soemba unter einem Namen zu vereinigen.

\section{6. d) Pseudagrion pilidorsum deflexum subsp. n.}

(Fig. 13 c.)

M a te ri a l: 13 o, S. Timor, Amarasi und Koepang, XII. 1931I. 1932, Ed. Handschin leg.

Durch die sehr verschiedene Gestalt der ô Appendices sofort zu erkennen. Diese sind bei allen Exemplaren gleich.

\section{Pseudagrion pruinosum pruinosum (Burm.).}

M a t e r i a l: 3 q (ad., sehr gut erhalten), Bali, Tirta Empol, I. 1932, Ed. Handschin; 1 q (juv., in Alkohol), N. Bali, Bratansee, $1100 \mathrm{~m}$, R. Woltereck leg.

Sichere pruinosum, von der vorigen Art leicht an den nur ganz wenig vorspringenden Mittellappen des Prothorax-Hinterrandes zu erkennen. Die Exemplare sind sehr alt und an den Thoraxseiten bläulich bereift, ganz ähnlich javanischen pruinosum. Die Art kommt auch im äussersten Osten der Insel Java häufig vor.

Das $q$ von Bratan ist stark verfärbt, gehört aber zweifellos hierher.

\section{Xiphiagrion cyanomelas (Selys).}

M a te ri a 1: 1 ô, W. Flores, Rana Mesé, 12-1300 m, 24. IX. 1932, R. Woltereck leg.; 46 ô, 21 o, W. Flores, Laboean Badjo, $100 \mathrm{~m}$ (5 ô, 1 우), Naga, 220 m (1 ㅇ, 12. XI. 1929), Wai Sano, Kratersee, 650 m (41 ô, 19 f), XI. 1929, J. K. de Jong leg.; ausserdem zahlreiche Larven aus dem Kratersee Wai Sano. - 1 9, N. E. Soemba, Kambera, III. 1925, K. W. Dammerman leg.

Eine enorm weit verbreitete und dazu recht variable Art. 
Die Serie der Kleinen Sunda-Inseln Flores und Soemba schliesst sich eng die von mir früher besprochene Form von Westjava an (Tijdschr. Ent., 72, 1929, p. 143-147, Fig. 34: Apps. ô). Sämtliche ô vom Kratersee Wai Sano, wo die Art nach DE Jong sehr häufig fliegt, sind relativ gross (Abd. 23-24, Hfl. $16 \mathrm{~mm}$ ) und ausgezeichnet durch das zeichnungslose blaue 8. Abdomensegment; die bronzeschwarzen Flecke auf dem Dorsum des 2. und 3. Abdomensegments sind nach vorn spitz verschmälert und erreichen den Vorderrand des Segmentes nicht. Die blauen Antehumeralstreifen sind vollständig und - wie bei javanischen Exemplaren - ziemlich breit. Die $\hat{o}$ von Laboean Badjo sind etwas kleiner (Abd. 20-22, Hfl. 13-14 mm). Die Rückenzeichnungen des 2. und 3. Segmentes sind nach vorn zwar stark verschmälert, aber doch, wie bei javanischen Stücken, mit dem Vorderrand verbunden; das 8. Segment ist bei $4 \hat{o}$ ganz blau, bei einem aber trägt es einen grossen, ovalen, schwarzen Rückenfleck, der mit dem Hinterrande blattstiel-artig zusammenhängt. Die Antehumeralstreifen wie bei Exemplaren von Wai Sano. Das ô von Rana Mesé, endlich, ist wieder grösser, in der Färbung des Abdomens jedoch nicht von den ô aus Laboean Badjo verschieden.

Die Appendices anales sind jenen javanischer Stücke durchaus ähnlich; die Superiores sind am Ende nicht eingeschnitten, wie bei Exemplaren von Simaloer, Celebes, den Molukken.

Das einzige $q$ von Soemba ist floresischen Exemplaren völlig gleich. Ein Versuch, das ganze Material der Ostverbreitung (Celebes, Molukken, Aroe-Inseln, Neu-Guinea) durchzuarbeiten, soll an anderer Stelle gemacht werden.

\section{Argiocnemis rubescens (Selys).}

M a te rial: $2 \hat{\jmath}, 1$ q, W. Flores, Laboean Badjo, $100 \mathrm{~m}$, XI. 1929, J. K. DE Jong leg.

Von westjavanischen Stücken der Ebene nicht verschieden.

20. Ceriagrion? erubescens (Selys).

(Fig. $17 a$, 18-19.)

M a t e ri a l: Nur eine Larve, von Timor (siehe Anhang). 


\section{Ischnura senegalens is (Ramb.).}

1934. Sснмidt, Arch. Hydrob., Suppl.-Bd. XIII, p. 341. - §̊우 Bali.

Mate rial: 2 ô, 4 , Bali, Tirta Empol und Karangasem, I. 1932, Ed. Handscinn leg. - 16 ô, 1 o, Lombok, Sapit, 600 m und Sambaloen, 1200 m, IV. 1896, H. Fruhstorfer leg. (Mus. Hamburg).

\section{A griocnemis femina (Brauer).}

1916. Ris, Supplem. Entom., 5, p. 23. - ô Lombok.

1934. Schmid T, Arch. Hydrob., Suppl.-Bd. XIII, p. 339. - §ج우 Bali.

M a t e r i a l: $11 \hat{\jmath}, 4$ +, $\mathrm{W}$. Flores, Mboera, $35 \mathrm{~m}$, und Laboean Badjo, 100 m, X-XI. 1929, J. K. DE Jong leg. - 1 ô (ad., grell weiss bereift), S. Timor, Amarasi, XII. 1931-I. 1932, Ed. Handschin leg.

Bei den $q$ von Flores ist der Prothorax-Hinterrand viel weniger als gewöhnlich in die Länge ausgezogen und daher in Seitenansicht kaum aufgerichtet. Dasselbe scheint in gewissem Grade nach Schмidт auch bei Exemplaren von Bali der Fall zu sein.

\section{ANISOPTERA.}

\section{Fam. Libellulidae.}

Unterfam. Libellulinae.

23. Tetrathemis irregularis hyalina (Kirby).

1909. Ris, Cat. Coll. Selys, Lib. fasc. IX, p. 47. - o Flores; 우 Timor.

M a te ri a l: 8 ô, 2 o, W. Flores, Laboean Badjo, $100 \mathrm{~m}$

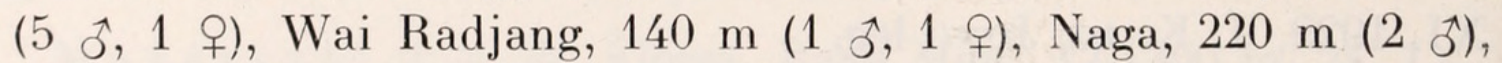
XI. 1929, J. K. De Jong leg. - 2 ô, 2 q, N. E. Soemba, Kambera, III. 1925 und E. Soemba, Kananggar, 700 m, V. 1925, K. W. Dammerman leg.

\section{Lyriothemis magnificata (Selys).}

1902. Kr ÜGER, Stett. ent. Zeitg., 63, p. 157-159. — ô Soemba (L. daui). 
25. Agrionoptera insignis insignis (Ramb.).

1909. Ris, Cat. Coll. Selys, Lib. fasc. X, p. 137. - 10 Flores; 10 Toemba.

\section{Potamarcha obscura (Ramb.).}

1909. Ris, Cat. Coll. Selys, Lib. fasc. X, p. 156. - Lombok; q Soemba.

M a t e ri a l: $2 \hat{\jmath}, 2$, , Bali, Tirta Empol, Kloengkoeng, Den Pasar, I. 1932, Ed. Handschin leg.; 1 ․, Bali, Karangasem, X.1928, P. F. Franck leg.; 1 ô, 5 ㅇ, E. Soembawa, Bima, XII. 1931, Ed. Handschin leg.

Sämtliche Exemplare sind wie die typische obscura des west lichen Gebietes gefärbt. Die Stücke von Soembawa sind nur ein wenig grösser.

\section{Orthetrum caledonicum (Brauer).}

1933. Lieftinck, Revue suisse Zool., 40, p. 428. - Timor (Notiz).

M a t e ri a l: 2 ô (ad.), S. Timor, Amarasi, XII. 1931- I. 1932, Ed. Handschin leg.

Diese schöne Art war bisher nur aus Australien und von einigen östlicheren Inselgruppen bekannt. Unsere Exemplare sind in der Färbung sehr schön erhalten, recht gross (Abd. 30-31, Hi1. 34 mm), aber sonst mit den Australiern völlig identisch.

\section{Orthetrum chrysis Selys.}

1909. Ris, Cat. Coll. Selys, Lib. fasc. X, p. 237. - ô Soembawa.

\section{Orthetrum glaucum (Brauer).}

1909. Ris, Cat. Coll. Selys, Lib. fasc. X, p. 234. - ํㅜㅇ Lombok; ํㅜㅇ S. Flores. 1916. Ris, Idem, fasc. XVI ${ }^{2}$, p. 1093. - ô Timor.

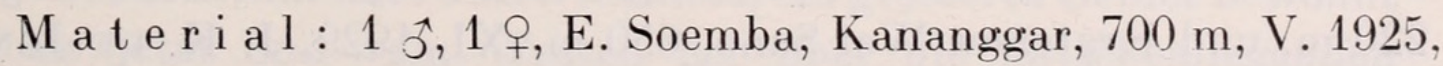
K. W. Dammerman leg.

Etwas kleiner als javanische Stücke; das Abdomen des ô weniger verbreitert, ungefähr wie bei den ô von Nordsumatra. 


\section{Orthetrum luzonicum (Brauer).}

1909. Ris, Cat. Coll. Selys, Lib. fasc. X, p. 210. - ô Soemba.

M a t e ria l: 1 ô (ad., verfärbt), E. Soemba, Kananggar, 700 m, V. 1925, K. W. Dammerman leg.

Ris gab keine Beschreibung seines $\hat{o}$. Das vorliegende Exemplar weicht bedeutend von luzonicum des westlichen Faunengebietes ab.

Oberlippe und Stirn sind völlig schwarz verdunkelt; die Beine sind auch schwarz. Beide Dreiecke im Hinterflügel sind durchquert, und die Genitalanhänge des 2. Abdomensegmentes sind auch ein wenig anders.

Die Art bildet sicher geographische Rassen; da mir aber keine Exemplare vom typischen Fundort (den Philippinen) vorliegen, bin ich jetzt nicht imstande, eine Gliederung des Formenkreises durchzuführen.

\section{Orthetrum pruinosum pruinosum (Burm.).}

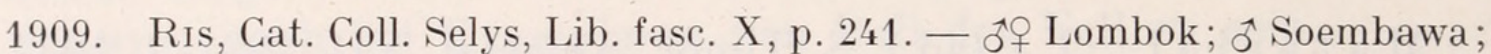
ô S. Flores.

1934. Schmidt, Arch. Hydrobiol., Suppl.-Bd. XIII, p. 379, 392. - ợ Bali.

M a t e ri a $1: 1$ ô (ad.), 6 o, W. Flores, Laboean Badjo, $100 \mathrm{~m}$

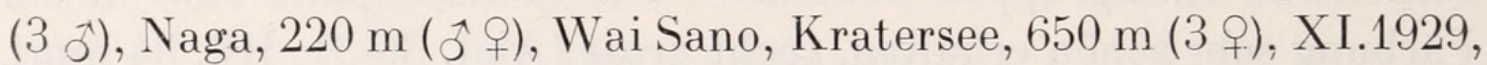
J. K. DE Jong leg.; 1 q (ad.), Flores, 1000 m, Ed. Handschin leg.

Ganz typisch; von javanischen pruinosum nicht zu unterscheiden.

\section{Orthetrum sabina (Drury).}

1916. Ris, Cat. Coll. Selys, Lib. fasc. XVI 2 , p. 1090. - ơ Timor.

1934. Schmid t, Arch. Hydrobiol., Suppl.-Bd. XIII, p. 379, 392. - Bali.

M a t e ria l: 1 으 (Beutetier von Anax guttatus), Bali, Kloengkoeng, I. 1932, Ed. Handschin leg.; 5 ๙ึ, 1 ‥, W. Flores, Naga, $220 \mathrm{~m}$, und Kratersee Wai Sano, $650 \mathrm{~m}$, XI. 1929, J. K. DE Jong leg.; 3 ô, 1 q, N. W. Soemba, Laora, 100 m, IV. 1925, K. W. Dammerman leg.; 1 q, N. Soemba, Waingapoe, I. 1932, Ed. HANDSCHIN leg. 


\section{3. a) Orthetrum testaceum testaceum (Burm.).}

1916. Ris, Cat. Coll. Selys, Lib. fasc. XVI 2, p. 1093-1094. - o 10 S. Timor (Lelogama, 800-1000 m, und Niki-Niki, $720 \mathrm{~m}$ ).

1934. Sсниid t, Arch. Hydrobiol., Suppl.-Bd. XIII, p. 379, 392. - ơ N. Bali, D. Bratan, $1100 \mathrm{~m}$.

M a t e ri a l: 1 ô (ad.), N. Bali, Gitgit, 500 m, 14. II. 1931, E. van Delden misit. - 1 ô (ad.), S. Timor, Amarasi und $1 \hat{o}$ (ad.), Soë, 830 m, XII. 1931-I. 1932, Ed. Handschin leg.

Das einzige $\hat{o}$ von Gitgit (Bali) ist identisch mit javanischen Stücken. Die zwei Männchen von Timor sind wie die von Ris erwähnten Exemplare, nur ein wenig kleiner, aber sonst fast gleich. Der Flügelbasisfleck ist hell goldgelb, relativ klein (wie bei javanischen testaceum). Der einzige Unterschied gegenüber westlichen Stücken liegt in den fast völlig schwarzen Tibien, die nur aussen an ihrer Basis die gewöhnliche lichtbraune Farbe aufweisen. Das Pterostigma ist eine Spur kürzer.

Länge: App. + App. 28, Hfl. 33, Pt. 2,7-2,8 mm.

Das Vorkommen der typischen Rasse auf der Insel Bali war zu erwarten und ist beachtenswert, weil schon auf Lombok die Rasse soembanum auftritt. Dass aber auf Timor nicht etwa O. testaceum soembanum, oder eine dieser nahestehende Form vorkommt, sondern eben der echte testaceum, ist ausserordentlich merkwürdig. In seiner Libellúlinen-Monographie hat schon Ris auf diese bemerkenswerte Tatsache hingewiesen, ohne eine Erklärung dafür zu geben. Es ist allerdings recht schwierig, dafür eine befriedigende Lösung zu finden. Es ist m. E. vollständig ausgeschlossen, dass die Subspecies soembanum etwa einem anderen Formenkreis als testaceum angehören dürfte und somit als distinkte - und vikariierende - Art anzusehen wäre; der Habitus ist gleich und Strukturdifferenzen fehlen gänzlich.

O. testaceum testaceum tritt in ganz wenig veränderter Form von Indien östlich bis Formosa, und südöstlich über die Grossen Sunda-Inseln hinaus bis Palawan und den Philippinen auf. Es ist aber einleuchtend, dass die Art damals ein grösseres Gebiet bewohnt hat als jetzt und vom Westen her über die zwischenliegenden Kleinen Sunda-Inseln auch Timor erreicht hat. Dass sie sich aber später von Lombok bis zur Alor-Inselgruppe (nordwestlich von Timor!) in völlig veränderter Rasse, soembanum, weitergebildet 
hat und auf Timor fast dieselbe geblieben ist, erscheint rätselhaft, da es wohl kaum mit klimatischen Einflüssen in Beziehung zu bringen ist. Es wäre recht interessant $\mathrm{zu}$ wissen, in welchem Kleide diese Art im nördlichen Teil der Insel Timor auftritt.

Wie bei test. soembanum habe ich auch bei den Exemplaren von Timor die Höhenlage der Fundorte --- soweit bekannt - möglichst genau angegeben.

\section{3. b) Orthetrum testaceum soembanum Förster.}

1903. Förster, Ann. Mus. Nat. Hung., 1, p. 542. - ô Soemba (O. test. Subrasse soembanum).

1909. Ris, Cat. Coll. Selys, Lib. fasc. X, p. 236. - ơ Lombok (Sapit, 600 m,

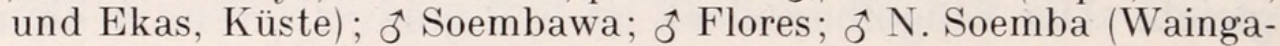
poe, Küste); ô Flores; ô Alor (O. test. sumbanum).

M a t e ri a l: 15 ô, 2 f, W. Flores, Laboean Badjo, $100 \mathrm{~m}$

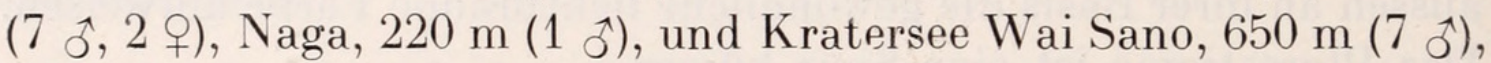
XI. 1929, J. K. de Jong leg.; 1 ô, Flores, 500 m, XII. 1931, Ed. Handschin leg.; 5 ô, 1 + , N. W. Soemba, Küstengebiet bij Laora, 100 m, IV. 1925 (2 ô) und E. Soemba, Kananggar, 700 m, V. 1925 (3 ô, 1 9), K. W. Dammerman leg.

Grössenunterschiede zwischen Exemplaren von Flores und Soemba im Allgemeinen wie bei Ris (loc. cit.) angegeben; in unserer Serie von W. Flores sind jedoch auch kleinere $\hat{o}$ vertreten, die sich von soembanischen Stücken nicht unterscheiden lassen. Flügelbasisfleck im Hinterflügel bei adulten Exemplaren tief dunkel goldbraun mit roten Adern.

Die $\hat{o}$ Genitalien am 2. Abdomen-Segment sind identisch mit denjenigen von testaceum und der Hamulus ist nicht, wie Förster behauptet, verschieden gestaltet.

In der Beschreibung bei Ris (p. 236 unten) soll es $q$ anstatt $C u q$ heissen.

\section{Brachydiplax duivenbodei (Brauer).}

M a t e r 1 a l: $1 \hat{\jmath}$ (ad.), W. Flores, Laboean Badjo, $100 \mathrm{~m}$, XI. 1929, J. K. DE Jong leg.

Ein ziemlich unerwarteter Fund; die Art war bisher nicht weiter westlich als Toli-Toli und Manado in Nordcelebes bekannt. Ihr Hauptverbreitungsgebiet liegt wahrscheinlich in Neu-Guinea. 
Sichere duivenbodei, aber ausgezeichnet durch etwas längeres und breiteres Abdomen (Abd. + App. 19, Hfl. 21 gegen etwa 18, 19 bei hiesigen Stücken von Neu-Guinea). Die Unterlippe ist in der Mitte breit schwarz. Das $t$ und $t i$ des Vorderflügels ohne Querader. Die Art ist von denticauda (Brauer) leicht $\mathrm{zu}$ unterscheiden an der glänzend violettmetallischen Stirn und Scheitelblase; auch das viel kleinere und schmälere Pterostigma und die 7 Antenodalqueradern sind charakteristische Merkmale.

35. Acisoma panorpoides (Ramb.).

1900. Kirby, Ann. Mag. Nat. Hist. (7), 5, p. 534. - Lombok.

1934. Scнmidt, Arch. Hydrobiol., Suppl.-Bd. XIII, p. 380,392 . - ô Bali.

M a t e ri a l: $3 \hat{\jmath}, 1$ q, W. Flores, Mboera, $35 \mathrm{~m}$ und Wai Radjang, 140 m, X. und 18. XI. 1929, J. K. DE Jong leg.

36. Diplacodes trivialis (Ramb.).

1911. Ris, Cat. Coll. Selys, Lib. fasc. XII, p. 468. - 후 Lombok.

M a te ria l: 1 \%, Bali, 1. XII. 1929, Miss C. Longfield ; 1 q, Bali, Karangasem, X. 1928, P. F. Franck leg.; 1 ô, N. E. Soembawa, Bima, XII. 1931, Ed. Handschin leg.; 1 ^̊, W. Flores, Wai Radjang, 18. XI. 1929, J. K. De Jong leg.; 1 ^ N. W. Soemba, Laora, IV 1925 und 1 ๙ै, N. E. Soemba, Kambera, III. 1925, K. W. Dammerman leg.; 1 q, N. Soemba, Waingapoe, I. 1932, Ed. Handschin leg.

37. Diplacodes haematodes (Ramb.).

M a t e ri a l : 1 ô (ad.), S. Timor, Amarasi, XII. 1931- I. 1932, Ed. Handschin leg.

Die Art wird hier zum ersten Male ausserhalb der Australischen Region (im Sinne Boden Kloss', 1929) erwähnt. Von nordaustralischen Stücken nur verschieden durch die etwas mehr reduzierte und blasser gelbliche Flügelbasis; sonst gleich. 


\section{Crocothemis servilia (Drury).}

1911. Ris, Cat. Coll. Selys, Lib. fasc. 13, p. 540. - ô Lombok; đُج Soembawa.

M a terial: 1 9, N. E. Soembawa, Bima, XII. 1931, Ed. Handschin leg.; 3 , W. Flores, Laboean Badjo und Mboera, X-XI. 1929, J. K. DE Jong leg.

Die weitverbreitete, im Westen sehr gemeine, gegen Osten aber allmählich an Häufigkeit abnehmende Art, bildet geographische Rassen, deren Begründung seit der von Ris gegebenen Zusammenfassung noch immer aussteht.

Das $q$ von Bima (Soembawa) ist von javanischen Stücken nicht verschieden; die floresischen Weibchen sind aber deutlich etwas kleiner und gedrungener gebaut; die Flügel sind weniger langgestreckt und das Abdomen ist kürzer. Ich habe leider noch kein einziges $\hat{\sigma}$ von den kleinen Sunda-Inseln gesehen.

39 a. Neurothemis palliata palliata (Ramb.).

M a te rial: $2 \hat{\jmath}, 2$ q (iso- und heterochrom), W. Flores, Laboean Badjo, 100 m, XI. 1929, J. K. DE Jong leg.; 1 q (heterochrom), S. Flores, Endé, Kalimoetoe, XII. 1931, Ed. Handschin leg.

Typische palliata, mit nur 1 Cuq im Hinterflügel. Braune Zeichnung im Vorderflügel bis etwa halbwegs vom Nodus zum Pterostigma, oder ganz bis zum Pterostigma; im Hinterflügel ebenso variabel, aber im Bogen zur Schleifenspitze und von da bis zum Winkel noch eine Zellreihe am Rande hyalin bleibend. Die heterochromen $q$ von Laboean Badjo und Endé haben stark gelbliche Flügelbasen, deren Farbe nach aussen ganz allmählich in fast hyalin übergeht; Spitzen grossfleckig, diffus dunkelbraun, nach innen höchstens bis etwas proximal vom proximalen Ende des Pterostigmas reichend. Nur 1 Cuq im Hinterflügel.

39 b. Neurothemis palliata var. ramburi (Brauer).

1911. Ris, Cat. Coll. Selys, Lib. fasc. XIII, p. 556. — $q$ Soemba.

M a t e r i a l: 23 ô (ad.), 5 q (ad., isochrom), W. Flores, Laboean Badjo, Wai Radjang, Naga, und Wai Sano (Kratersee), 100-650 m, 
X-XI. 1929, J. K. DE Jong leg.; 1 q, E. Soemba, Kananggar, 700 m, V. 1925, K. W. Dammerman leg.

Die Mehrzahl der floresischen $\hat{o}$ der palliata gehört der Varietät ramburi an. Eine schöne und sehr homogene Serie; die Zeichnung im Vorderflügel ist recht scharf begrenzt und reicht gerade abschliessend genau bis zum Nodus; im Hinterflügel ebenso und im Bogen zur Schleifenspitze, von da bis zum Winkel noch eine Zellreihe hyalin bleibend. Die Körpergrösse ist ziemlich variabel. Nur ganz ausnahmsweise mehr als 1 Cuq im Hinterflügel.

Bei den $q$ ist die Ausdehnung der Flügelzeichnung etwas variabel und im Ganzen weniger weit distal reichend: im Vorderflügel meist etwa 3-4 Zellen, im Hinterflügel etwa 2 Zellen proximal vom Nodus abschliessend, der Aussenrand gerade oder leicht convex, den Hinterrand mit einbeziehend; nur bei einem $q$ ist die Färbung gleich dem $\hat{\delta}$.

Das $\hat{o}$ von Soemba ist identisch mit denjenigen von Flores.

\section{Neurothemis terminata terminata Ris.}

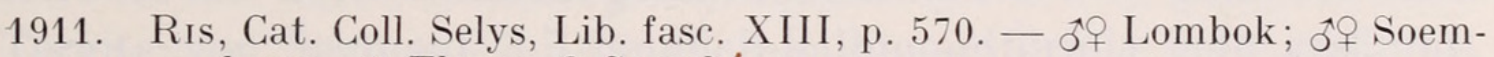
bawa; ô Flores; + Soembà.

M a t e r i a l: 2 ô, Bali, Tirta Empol, I. 1932, Ed. Handschin leg.; 1 ô, 2 o (heterochrom und isochrom), N. E. Soembawa, Bima, XII. 1931, Ed. Handschin leg.; 2 ô, N. W. Soemba, Laora, 100 m, IV. 1925, K. W: Dammerman leg.

Typische terminata, mit javanischen Exemplaren vollig identisch und in gleichem Masse etwas variabel.

\section{Rhodothemis rufa (Ram.).}

M a t e ri a l: 2 ô (1 juv.), W. Flores, Laboean Barjo, $100 \mathrm{~m}$, XI. 1929, J. K. DE Jong leg.

Relativ kleine, gedrungen gebaute Exemplare mit goldbraunem Flügelbasisfleck.

\section{Trithemis aurora (Burm.).}

1934. Schmidt, Arch. Hydrobiol., Suppl.-Bd. XIII, p. 383, 392. - ợ Bali.

M a t e r i a l: $14 \hat{\jmath}, 3$ o, W. Flores, Mboera, 35 m (6 §) $)$, Laboean Badjo, 100 m (6 ô, 2 ㅇ), Naga, 220 m (2 ิ, 2 우), X-XI. 1929. 
J. K. De Jong leg.; 5 ô, 1 ㅇ, E. Soemba, Mao Marroe, 600 m, und Kananggar, 700 m. V. 1925, K. W. Dammerman leg.; 6 §ै, 1 ; S. Timor, Amarasi, XII. 1931-I. 1932, Ed. Handschin leg.

Ohne Besonderheiten.

\section{Trithemis festiva (Ram.).}

1912. Ris, Cat. Coll. Selys, Lib. fasc. XIV, p. 797. - ô Lombok; ô Flores; ô Alor.

1934. Schmid t, Arch. Hydrobiol., Suppl.-Bd. XIII, p. 384, 392. - ô Bali.

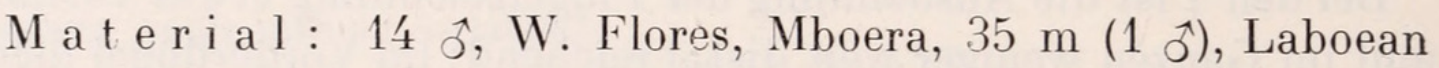
Badjo, 100 m (7 j)), Wai Radjang, 140 m (6 ô), X-XI. 1929, J. K. DE Jong leg.; 2 ô, Flores, Todabeloe, m, XII. 1931, Ed. Handschin leg.; 2 ô, N. E. Soemba, Kambera, III. 1925, und 3 วิ, Kananggar, 700 m, V. 1925, K. W. Dammerman leg.; 1 ô, S. Timor, Amarasi, XII. 1931, Ed. Handschin leg.

\section{Trithemis lilacina Förster.}

1899. Förster, Ann. Soc. ent. Belg., 43, p. 63-64. - ô Soembawa.

1912. Ris, Cat. Coll. Selys, Lib. fasc. XIV, p. 766. - ô Lombok; ô Soembawa; ô Flores; ô Pantar; ô Soemba.

M a te ri a 1: 2 ô (ad.), W. Flores, Naga, 220 m, 12. XI. 1929, und 1 ô (ad.), idem, Wai Radjang, 140 m, 18. XI. 1929, J. K. DE Jong leg.; 1 ô (ad.), E. Soemba, Mao Marroe, $600 \mathrm{~m}$, und $4 \hat{\jmath}$, 1 ㅇ (ad.), idem, Kananggar, 700 m, V. 1925, K. W. Dammerman leg.

Mit den Beschreibungen gut übereinstimmend. Die Masse sind dieselben wie die von Förster angegebenen. Anq $\frac{13 \frac{1}{2}-14 \frac{1}{2}}{9-10}$.

Der tief dunkelbraune Basisfleck im Hinterflügel ist bei den Exemplaren von Soemba etwas mehr reduziert (bis $A n q$ 1, und etwas über $C u q)$.

우 (ad., Soemba, A 1 l ot y p e ). - Unterlippe gelb, der Mittellappen schwarz. Oberlippe gelb, in der Mitte ein schwarzer Basalpunkt und am Rande breit schwarz gesäumt. Gesicht trüb gelbbraun. Stirn orangegelb, oben nur an der Basis mit stark blaumetallisch glänzenden Streifen; Scheitelblase vorn braun, hinten blaumetallisch. Occipitaldreieck gelblich, Occiput schwarz, am Augenrand gelb gefleckt. 
Prothorax wie beim $\hat{0}^{\wedge}$. Thorax oben düster olivgelb, innen entlang der Schulternaht verdunkelt. Seitenbinden hell grünlichgelb, schwarze Nahtstreifen schärfer begrenzt und etwas breiter als beim $\widehat{\jmath}$. Beine schwarz; Coxen gelbbraun. Basales Zweidrittel der Vorderschenkel und basales Drittel der Mittelschenkel innen mit gelbem Streifen.

Abdomen nur an der Basis sehr wenig erweitert, sonst fast cylindrisch, breiter als beim $\hat{\jmath}$. Hell gelbbraun, oben von der Mitte des 3 . Segmentes an nach hinten etwas dunkler, mehr nach sepiaund rötlichbraun; 1. dorsal schwarz, Hinterrand in der Mitte fein gelb gerandet, seitlich hellgelb; Segment 2 hellgelb, vorn und hinten schwarz gerandet, seitlich hinten ein kleiner schwarzer Vorsprung; 3.-7. auf der Dorsalkante eine ziemlich breite, scharfbegrenzte schwarze Linie, an den Lateralkanten eine viel breitere, vorn gegabelte, schwarze Binde, die auf Segment 5-7 hinten etwas verbreitert ist, sodass die paarigen gelben Rückenflecken hinten ein wenig verschmälert sind. Articulationen schwarz. Segment 8 schwarz mit dorso-basalem gelbbraunem Fleck, 9-10 ganz schwarz. Tergite von Segment 3-5 länglich-halbmondförmig gelb gesäumt. Sternite schwarz.

Flügel sehr leicht graugelb getrübt, fast hyalin. Adern und Pterostigma schwarz. Der Basisfleck ganz klein, goldgelb, im Umfang etwa die Hälfte kleiner als beim $\hat{o}$, in $s c$ bis halbwegs $A n q$ 1. und in cü bis halbwegs $C u q$, diffus begrenzt.

Trithemis lilacina ist die einzige Libelluline, die auf die Kleinen Sunda-Inseln beschränkt ist. Es ist nun eine recht interessante Tatsache, dass sie bisher noch nicht auf Bali gefunden wurde; der Beweis ihres dortigen Fehlens kann aber noch erbracht werden.

\section{Zygonyx ida ida Selys.}

1912. Ris, Cat. Coll. Selys, Lib. fasc. XIV, p. 819. - oto Lombok; + Timor.

\section{Zyxomma obtusum Albarda.}

1913. Ris, Cat. Coll. Selys, Lib. fasc. XV, p. 908-909, Fig. 528 (Flügel ^ึ, Lombok). - ô Lombok.

M a t e ri a l: 6 ô (ad.), S. E. Bali, Kloengkoeng, I. 1932, Ed. Handschin leg., mit der Sammelnotiz "fliegt abends". 
Über die Lebensweise dieser Abendflieger habe ich in Treubia, XIV, 1934, ausführlich berichtet. Von javanischen obtusum nicht verschieden.

\section{Tholymis tillarga (F.).}

M a te ria l: $1 \hat{\jmath}$, S. E. Bali, Kloengkoeng, I. 1932, Ed. Handschin leg. - 1 \&, S. Flores, Endeh, XII. 1931, Ed. Handschin leg. - 1 ふै, N. E. Soemba, Kambera, III. 1925, K. W. Dammerman leg.

\section{Pantala flavescens (F.).}

M a t e ri a l: 2 o, S. Bali, Den Pasar, I. 1932, Ed. Handschin leg.; 1 q idem, Kintomani, 15. V. 1929 (Sammler nicht genannt). - 1 ô, Insel Kisar (Kisser), nördl. Timor, 17. XII. 1929, Miss C. Longfield leg. (in litt.).

Sonderbarerweise war diese überall häufige und kosmopolitische Libelle noch nie von der Inselkette erwähnt worden. Sie kommt aber zweifellos auf allen Kleinen Sunda-Inseln vor. Vom Nachbargebiet habe ich Exemplare gesehen von Kangean, Saleyer und Tenimber (Timorlaoet).

\section{Camacinia gigantea (Brauer).}

1869. Hagen, Stett. ent. Zeitg., 30, p. 94. - Timor (Neurothemis).

1902. KrüGER, Ibid., 63, p. 105. - Kisar (Kisser).

1913. Ris, Cat. Coll. Selys, Lib. fasc. XV, p. 926. - o Lombok; ô Soemba; ô Timor.

Die Art hat eine weite insuläre und Küstenverbreitung, was zweifellos mit ihrer Lebensweise zusammenhängt. Wie ich während meines Aufenthaltes in den Karimoen Djawa-Inseln (Java-See) feststellen konnte, bevorzugt Camacinia dort die Mangrove Zone und die angrenzenden Reisfelder. Die Larven sind imstande einen relativ hohen Salzgehalt des Wassers zu ertragen.

\section{Rhyothemis phyllis (Sulzer) subspec.}

M a terial: 1 9 , W. Flores, Mboera, 35 m, X. 1929, J. K. DE Jong leg. - 1 + , E. Soemba, Kananggar, 700 m, V. 1925, K. W. Dammermann leg. 
Das leider sehr kleine Material ist ungenügend, diese zweifellos gute Rasse schon jetzt gegenüber den besser begründeten Subspecies des Nachbargebietes abzutrennen. Obgleich mir noch keine $\hat{o} \widehat{o}$ vorliegen, möchte ich oben erwähnte Inselrasse doch einmal benennen, hoffe aber später im Zusammenhang näher auf diese Form einzugehen.

\section{Rhyothemis regia (Brauer) subspec.}

1913. Ris, Cat. Coll. Selys, Lib. fasc. XV, p. 951-952, Pl. VI (col. Abbdg. der Flügel). - + Soemba ( $R$. regia exul).

Das einzige, bisher von den Kleinen Sunda-Inseln bekannt gewordene Exemplar ist das von Ris abgebildete und provisorisch unter exul gestellte $q$ von Soemba. Es handelt sich hier m. Fi. fast sicher um eine eigene Rasse, deren Begründung bis auf Näheres verschoben werden muss. Ris (loc. cit) hat schon bemerkt: "Warscheinlich wird mit Kenntnis von genügendem Material eine besondere Form der Kleinen Sunda-Inseln zu beschreiben sein, die sich vielleicht enger an die Form von Kei [exul] als an solche aus andern Teilen des Verbreitungskreises anschliesst ».

\section{Rhyothemis graphiptera (Ramb.).}

M a t e ri a l: 1 q (ad.), S. Timor, Kepang, XII. 1931-I.1932, Ed. Handschin leg.

Diese schöne Art war vorher, ausser von Neu-Caledonien und Australien, auch vom südlichen Neu-Guinea, den Aroe-Inseln und von der Molukkeninsel Boeroe bekannt. Timor ist der westliche Vorposten ihres Verbreitungsgebietes; sie dürfte dort wohl sicher von Nordaustralien her eingewandert sein.

Wie schon von Ris in seiner Monographie (loc. cit., p. 934) bemerkt wurde, ist die Variabilität der Flügelzeichnung eine recht unbedeutende, und auch das vorliegende $q$ unterscheidet sich gar nicht von denjenigen des australischen Festlandes.

Rev. Suisse de Zool., T. 43, 1936. 


\section{Tramea limbata eurybia (Selys).}

1913. Ris, Cat. Coll. Selys, Lib. fasc. XVI a, p. 984-985. - §ơ Lombok; o Sawoe; $q$ Timor (T. limbata $\left.d^{3}-d^{4}\right)$.

Ich habe keine Exemplare gesehen. Die typische eurybia wurde ursprünglich nach einem $\hat{\jmath}$ aus Manado (N. Celebes) beschrieben, mit dem die Exemplare von Lombok und Sawoe (Savoe, zwischen Soemba und Timor) nach Ris sehr nahe übereinstimmen sollen. Eine revisorische Bearbeitung der orientalischen Tramea ist in Vorbereitung; ein Bruchstück dieser Revision soll in meiner NeuGuinea Monographie gegeben werden.

\section{Unterfam. Cordulinan.}

\section{Hemicordulia spec.}

1934. Schмidт, Arch. Hydrob., Suppl.-Bd. XIII, p. 377-378. — q Bali (Bratan-See, $1100 \mathrm{~m})$.

Eine Bestimmung dieser Art war ohne das ổ und ohne Vergleichsmaterial an verwandten Arten nicht möglich. Ich habe das Stück nicht gesehen.

\section{Procordulia sambawana (Förster).}

1899. Förster, Ann. Soc. ent. Belg., 43, p. 64-65. - ơ Soembawa (Somatochlora sambawana).

1906. Martin, Cat. Coll. Selys, Cordul. fasc. XVII, p. 17. - Lombok; Soembawa; Flores. (P. sumbaswana).

1930. Liefinck, Treubia, 12, p. 162-164. - Wie oben, und Soemba. (P. sumbaxana).

M a te ri a l: 2 ふै, E. Lombok, Sapit, 600 m, IV. 1896 und Ekas (Küste), V. 1896, ex coll. Fruhstorfer, Procordulia sumbawana Först., det. Ris. - 1 ô, Soemba (Fruhstorfer), in SELys' Handschrift; "Epitheca arctica Zett. " (Museums-Etikette), im Brüsseler Museum.

Das einzige ô von Soemba wurde von mir in der Europa-Sammlung der früheren "Collection de Selys Longchamps », im Brüsseler Museum, unter einigen Exemplaren der europäischen Somatochlora arctica Zett. entdeckt und mir zum Vergleich mit der 
javanischen sambawana von Herrn A. BALL freundlichst leihweise überlassen. In meiner früheren Darstellung (Treubia 1930) sprach ich die Vermutung aus, dass $P$ sambawana sich später vielleicht in geographische Rassen aufteilen liesse. Bei genauester Überprüfung einer sehr grossen Serie sambawana von Java und einiger Exemplare von Südcelebes glaube ich aber besser zu tun, die Art nicht zu zersplittern, vor allem weil die Differenzen zwischen javanischen Stücken und dem Material von Lombok und Soemba durch die kleine Serie aus Südcelebes ( $4 \hat{\jmath}$ und 1 으) vollständig überbrückt werden.

Sämtliche $\hat{\sigma}$ von den kleinen Sunda-Inseln (es sind deren freilich nur 3 !) haben regelmässig $2 \mathrm{Cuq}$ im Hinterflügel, wie beim Genus Somatochlora. Von den 5 Exemplaren aus Celebes hat nur das im linken Hinterflügel 2 Cuq, und bei javanischen Stücken ist das Vorhandensein zweier Queradern im Cubitalfeld eine grosse Seltenheit.

Wie Förster in seiner Originalbeschreibung angibt, sind die Appendices anales " munis d'une petite dent triangulaire à peu près au milieu du bord externe ». Ein solcher (ganz kleiner) Zahn ist bei unseren $\hat{\sigma}$ von Lombok und Soemba auch deutlich vorhanden, während er bei den Celebes-Stücken entweder gleichfalls sehr deutlich entwickelt ist, oder ganz fehlt. Bei der Mehrzahl der javanischen $\hat{o}$ fehlt er gänzlich, bei einem Teil des Materiales (vom Papandajan-Westjava, Slamat-Mitteljava und vom TenggerGebirge in Ostjava) ist ein Zahn aber mehr oder weniger deutlich vorhanden.

Ich glaube, dass es in diesem Fall und unter diesen Umständen unmöglich und unzulässig ist, diese offenbar inconstanten Strukturunterschiede als Rassenmerkmale zu benützen, zumal eben bei den Corduliinen Unregelmässigkeiten in der Flügelnervatur, wie auch kleine Schwankungen in der Form der oft sehr weichen männlichen Appendices anales recht häufig vorkommen.

\section{Epophthalmia vittigera (Ramb.).}

1931. Lieftinck, Treubia, 13, p. 66. - ô Timor.

Nach diesem Exemplar wurde die schöne farbige Abbildung in Martin's Cordulinae (Wytsman's Genera Insectorum, fase. 155. 
1914) angefertigt. Das Vorkommen dieser unverkennbaren Art so weit nach dem Osten ist merkwürdig, da sie z. B. auf Celebes nicht vorkommt und dort durch australis Hagen ersetzt wird. Ist das van Der Hoffen'sche Material aus Timor wohl ganz zuverlässig?

\section{Fam. Gomphidae.}

\section{Mesogomphus flavohamatus (Martin).}

1921. Martin, Ann. Soc. ent. France, 90, p. 95. - ơ (angeblich auch Boeroe) (Onychogomphus).

1934. Lieftinck, Tijdschr. Ent., 77, p. 19 (Tabelle), 27-30 (Fig. 3 und 5). oto Flores.

M a t e r i a 1: $1 \hat{o}, 1$ \&, Flores, Fruhstorfer, jetzt im Brüsseler Museum.

58. Mesogomphus tachyerges Lieftinck.

1934. Lieftinck, Tijdschr. Ent., 77, p. 19 (Tabelle), 30-33 (Fig. $3^{d}$ und 6). ô Soemba.

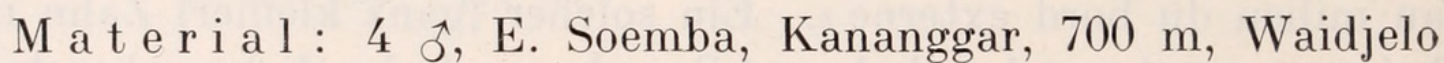
Fluss, V. 1925, K. W. Dammerman leg.

\section{Fam. Aeschnidae.}

\section{Gynacantha musa Karsch.}

Materia]: $1 \hat{\jmath}$, Flores (Fruhstorfer), in der Handschrift SElys' (Museum Brüssel).

Das Exemplar gehört zweifellos zu musa Karsch. Es stand unter den Namen basiguttata Selys in der alten Selys'schen Sammlung eingereiht. Obwohl Martin den Fundort Flores in seiner Monographie nicht nennt (nur " archipel de la Sonde, Philippines, Birmanie »), wurde dieses ô sicher von ihm hieher gestellt.

Eine sehr gute Figur der $\hat{o}$ Appendices findet sich ebendort (p. 189, Fig. 193). Die Art ist unverkennbar.

60. Gynacantha subinterrupta (Ramb.).

1909. Martin, Cat. Coll. Selys, Aeschnines, fasc. XX, p. 201-202. - Lombok (G. kirbyi).

1915. Ris, Nova Guinea, 13 Zool., 2, p. 110. - Lombok. 
Martin's Angabe der G. kirbyi von Lombok bezieht sich mit grosser Sicherheit auf subinterrupta. Die zweifelhafte Natur seiner Bestimmung wurde schon von Ris hervorgehoben (Abh. Senckenb. Naturf. Ges., 34, 1913, p. 525). Auch Martin's Angabe "Lombok» für Gynacantha mocsaryi Förster ist sicher falsch (vgl. Ris, loc. cit., p. 523).

Nur die beiden obengenannten Arten musa und subinterrupta sind jetzt sicher für die Kleinen Sunda-Inseln festgestellt.

\section{Anaciaeschna jaspidea (Burm.).}

1908. Martin, Cat. Coll. Selys, Aeschnines, fasc. XVIII, p. 31. - Lombok. 1910. Ris, Die Fauna Südwest-Australiens, 2, 24, p. 434, Fig. 14-15. - ợ Lombok.

\section{Anax gibbosulus (Ramb.).}

1898. Kr ÜG ER, Stett. ent. Zeitg., 59, p. 272-274. — ô Soemba (A. gibbosulus). 1933. Lieftinck, Revue suisse Zool., 40, p. 437. - Flores; Soemba (A. gibbosulus).

M a t e r i a l: 2 ㅇ, W. Flores, Kratersee Wai Sano, 6. XI. 1929, J. K. DE Jong leg.; 2 ^ิ, 1 ㅇ, N. W. Soemba, Laora, 100 m, IV. 1925 und 1 q, E. Soemba, Kananggar, 700 m, V. 1925, K. W. Dammerman leg.

Ueber diese grosse Anax-Species ist augenblicklich nichts neues auszusagen. Man vergleiche meine Bemerkungen loc. cit. 1933, und die Erörterungen dazu unter gibbosulus in meiner Java-Liste (Treubia, 14, 1934, p. 448-449).

Eine illustrierte Bearbeitung der austromalayischen Vertreter der Gattung ist dem IV. Teil meiner Arbeit in "Nova Guinea " vorbehalten.

\section{Anax guttatus (Burm.).}

1933. Lieftinck, Revue suisse Zool., 40, p. 438 (Fussnote). - Kisar ( $A$. gibbosulus).

M a te ri a l: 1 $\hat{o}$ (ad.), S. E. Bali, Kloengkoeng, I. 1932, Ed. Handschin leg.

Während der Drucklegung meiner Arbeit über "Odonaten aus Nordaustralien ») (loc. cit.), erhielt ich eine briefliche Mittellung von Miss C. Longfield in London, dass ihre zuerst als gibbosulus 
bestimmte Anax-Art von Kisar (Kisser, nordöstlich von Timor) tatsächlich zu guttatus gestellt werden muss. Leider war ich nicht mehr imstande, meine diesbezügliche Notiz in obengenannter Schrift zu korrigieren.

Das jetzt vorliegende $\hat{\sigma}$ von Bali ist ganz typisch und mit javanischen Stücken identisch.

\section{ANHANG: LARVEN.}

\section{Lestes praemorsus Selys (?).}

(Fig. 14.)

M a t e r i a 1: 8 Exemplare (1 ô, 6 qult., 2 क penult.) von Timor,

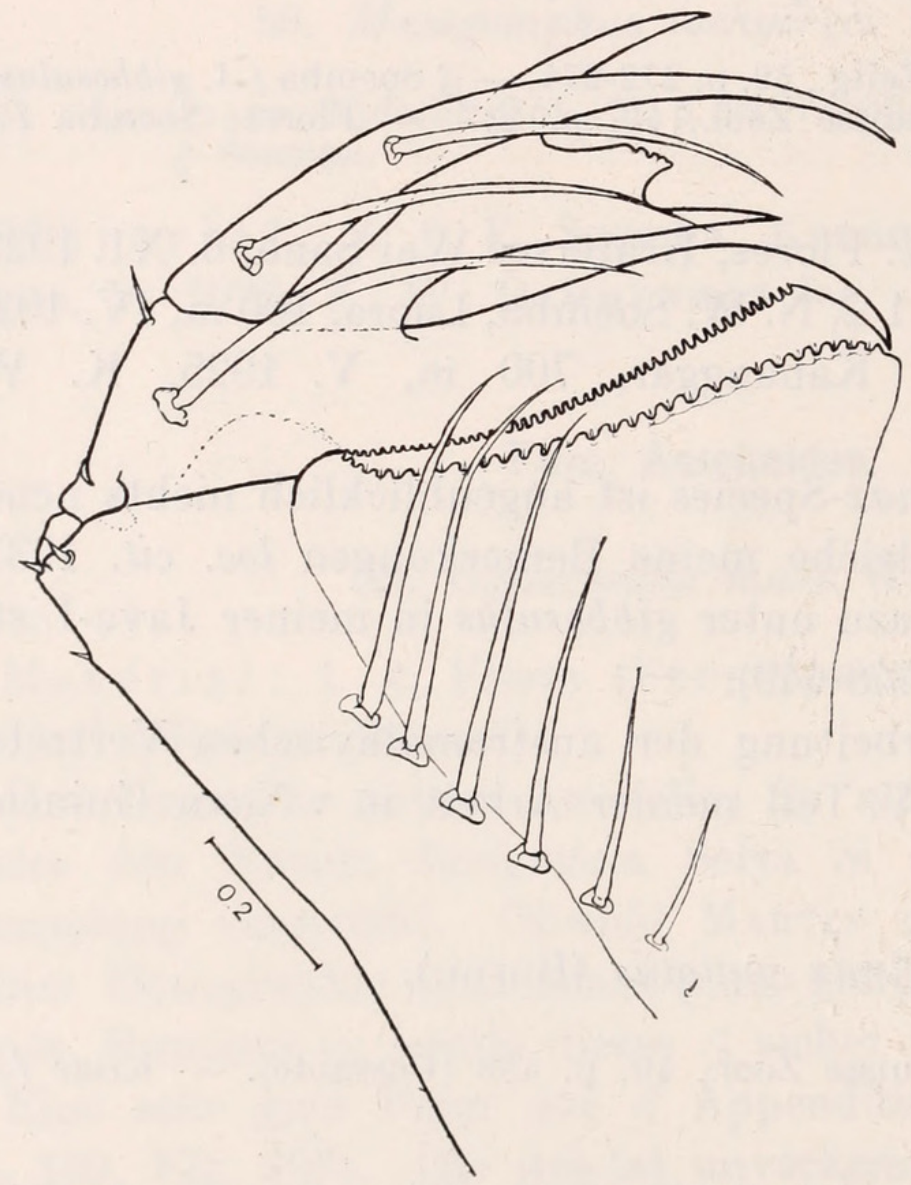

FIG. 14. - Lestes ? praemorsus Sel., Timor.

Ende des Labium, linke Hälfte der Innenseite. ohne weitere Angaben, Mrs. M. E. Walsh leg. et don.

In meiner Schrift über Odonaten von der Molukkeninsel Boeroe (Treubia, 7 Suppl., 1930, p. 319320 , Pl. VI) wurde das vorletzte Larvenstadium dieser Art ausführlich beschrieben und abgebildet. Vorliegendes Material ist ausser in den Farben gut erhalten und gestattet einen direkten Vergleich mit dem Exemplar von Boeroe. Die Larven sind durch Alkohol stark entfärbt, stimmen aber in der Form und Zeichnung der Tracheenkiemen fast völlg mit dem einzigen $\hat{o}$ von Boeroe überein. 
Körperlänge (ohne Kiemen) 15,5-16; medianes Blatt 8,70, laterales Blatt $<9 \mathrm{~mm}$.

Die Art wurde als praemorsus bestimmt, da die Form und Zähnelung des Labiums in allen Einzelheiten mit meiner Figur in "Treubia » übereinstimmt. Da aber über austromalayische Lestes-Larven bisher nichts weiteres in der Literatur zu finden ist (auch die Larve von $L$. concinnus Selys ist noch unbekannt), bleibt die Zugehörigkeit unserer Timor-Exemplare zu praemorsus etwas fraglich.

Die Anzahl der Borsten auf dem Mentum ist ein wenig variabel; sämtliche ausgewachsenen Exemplare haben jederseits sechs nach aussen allmählich länger werdende Borsten; bei einem penult. + gibt es deren aber nur fünf. Das Labium ist sehr lang und schlank (Basalstück oder Mentum 4,5 mm) und reicht nach hinten fast bis zum Ende des Poststernums über die Coxen des 3. Beinpaares hinaus. Die Seitenranddornen der Abdomensegmente 9-7 kräftig, 6 deutlich kleiner.

Ich gebe noch eine Abbildung des Labiums (Fig. 14).

\section{Xiphiagrion cyanomelas Selys.}

(Fig. 15-16, 17 b.)

M a t e ri a l: Viele Exemplare, grösstenteils erwachsen von W. Flores, Kratersee Wai Sano, 650 m, XI. 1929, J. K. De Jong leg. - Viele Exemplare, W. Java, G. Tangkoeban Prahoe, 1450 m, Kraterplateau zwischen Kawah Domas und Kawah Djarian, schwefelhaltiges, langsam fliessendes, warmes Wasser (Temperatur ca. $42^{\circ}$ C.) ohne Vegetation, 27. X. 1929, Autor leg. - Viele Exemplare, N. Celebes, Minahassa, Linoo See, 5. VI. 1932, R. Woltereck leg. Dazu die Bemerkungen des Sammlers: "Temp. 27, $8^{\circ}, p^{\mathrm{H}} 4,0$; Libellen schwärmen zu Tausenden wie Ephemeriden. Larven an Laubbüscheln in belieb. Menge gefangen, geröstet u. gegessen " (letztere Notiz bezieht sich wahrscheinlich auf die ebenfalls in Anzahl vorliegenden Larven der Orthetrum pruinosum clelia Selys).

Leider ist es an dieser Stelle nicht möglich, die Larve von Xiphiagrion mit denjenigen anderer Agrionidengattungen, wie Ischnura, Aciagrion, Mortonagrion und Argiocnemis $\mathrm{zu}$ vergleichen und eingehend zu behandeln, da sich diese Uebersicht sonst alsbald zu einer umfangreichen Abhandlung ausdehnen würde; ausserdem 
liegen mir die genannten Genera wohl vom westlichen Teile des malayischen Archipels, nicht aber von den Kleinen Sunda-Inseln vor. Es empfiehlt sich aber wohl, die leicht kenntliche Xiphiagrion-

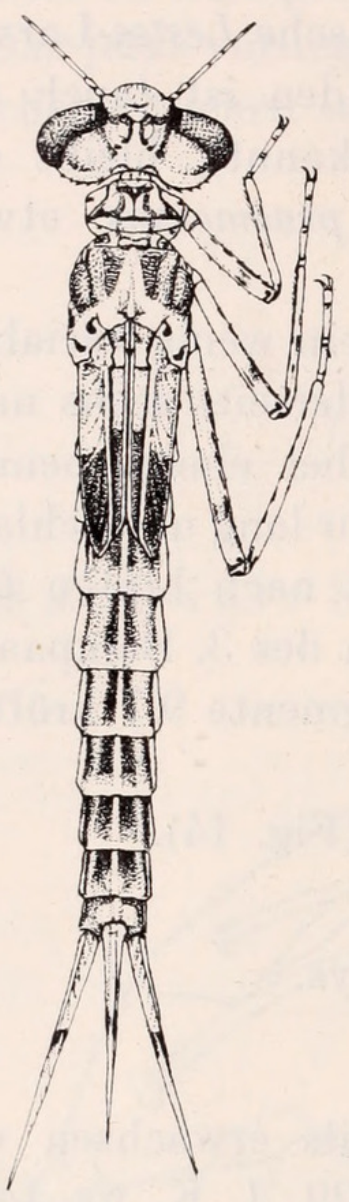

FIG. 15.

Xiphiagrion cyanomelas Selys, Flores.

Erwachsene Larve.

ten ein wenig überschreitend, an der Basis sehr schmal, nach dem Ende stark dreieckig erweitert. Lab.-Ml. dreieckig vorspringend, am Rande mit microscopisch schwacher Zähnelung. Jederseits 4 mentale, 5 laterale Borsten. Lab.-Sl. deutlich zweigeteilt, der laterale Anteil quer abgestutzt, aber medianwärts mit drei kräftigen Endzähnen,
Larve abzubilden und kurz ihre wichtig sten Charakteristika zu erwähnen.

Larve von W. Flores. - Wenig durchscheinend, schlank. Kopf ziemlich gross, Postocularloben abgerundet. Gelbbraun; Mesothorax oben und seitlich rötlichbraun, distale Hälfte der Flügelscheiden scharf abgegrenzt dunkelbraun. Augen bleiblau verfärbt. Antennen lang, 2,06 mm, Länge der einzelnen Glieder : 0,24, 0,33, 0,60, 0,3,5 $0,26,0,17,0,11 \mathrm{~mm}$. Beine mit schwach bräunlicher Ringelzeichnung. Form und Zeichnungen übrigens wie aus Figur 15 ersichtlich.

Labium kurz, das Gelenk dem Körper anliegend und das 1. Beinpaar nach hin-

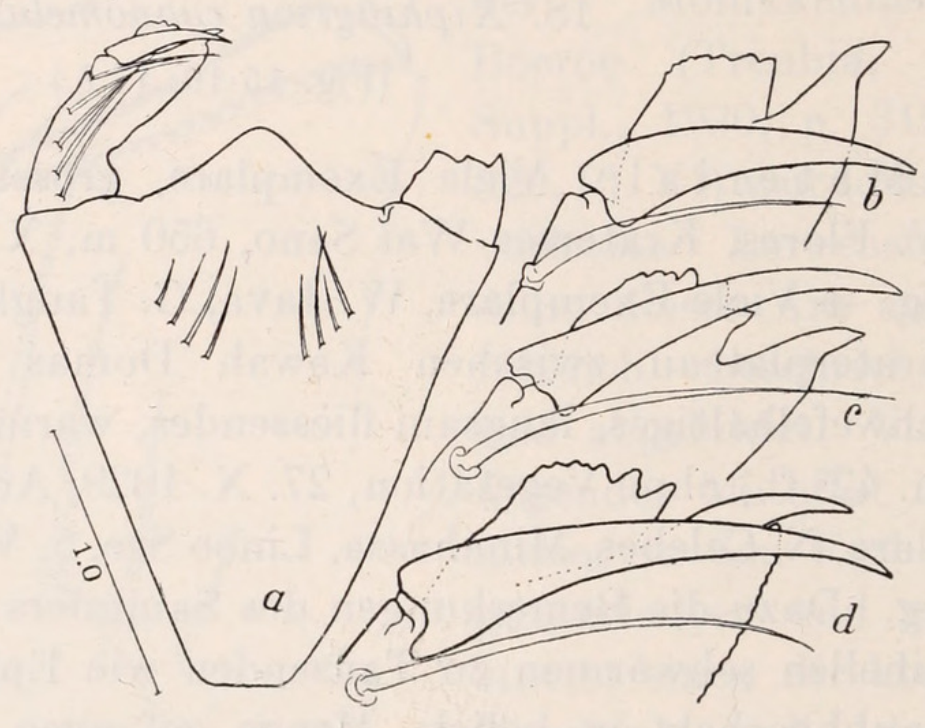

FIg. 16. - Xiphiagrion cyanomelas Selys.

a) Labium von der Innenseite (Flores); $b$ )-d) Endteil der Seitenlappen des Labium; b) Java; c) Flores; d) Celebes, stärker vergrössert. 
lateralwärts in 3 oder 4 undeutliche Zähnchen übergehend; der mediane Anteil mit hakenförmigem, relativ kurzem Endzahn (Fig. 16).

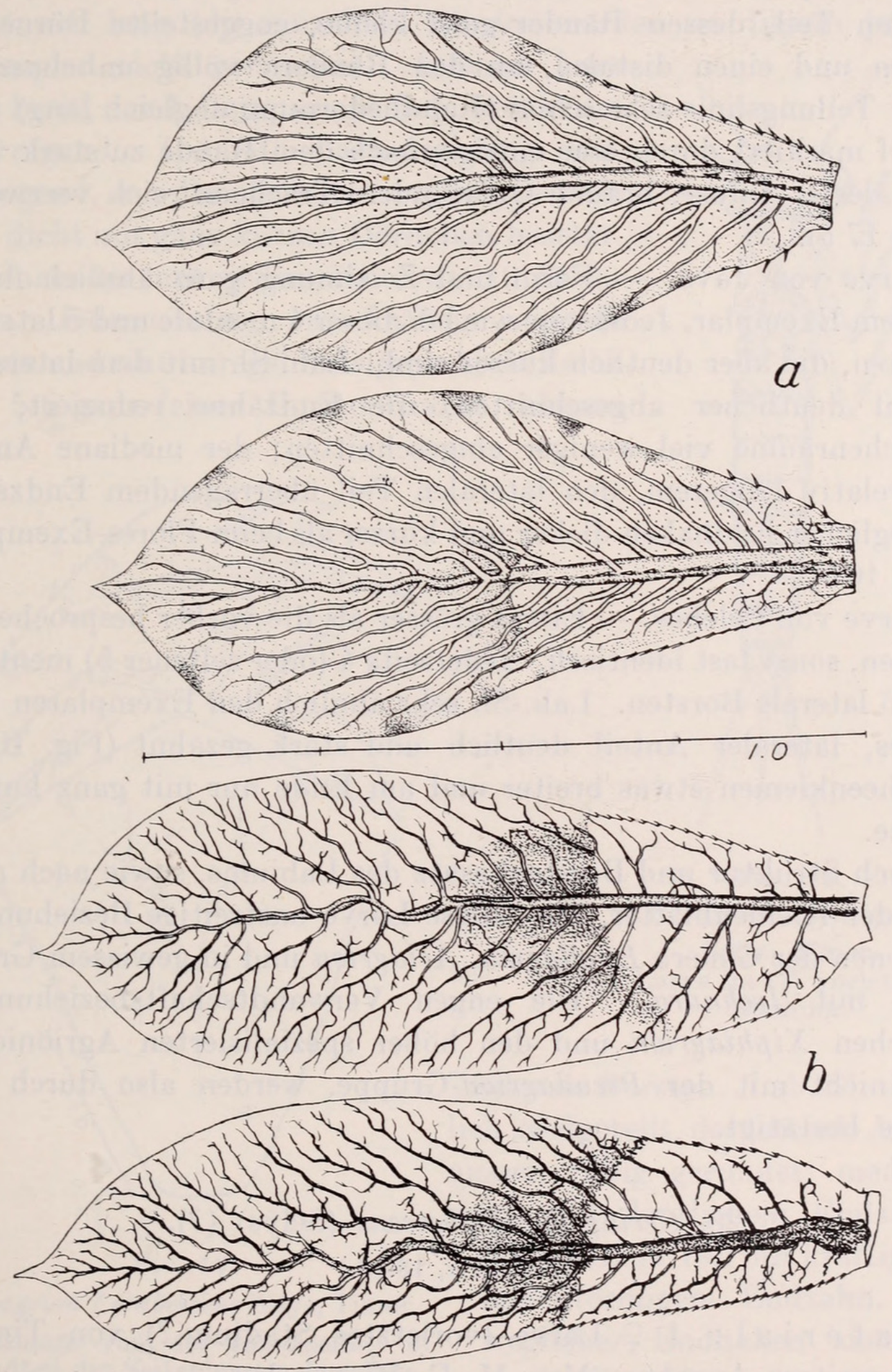

FIG. 17.

Caudale Kiemenblätter der Larve von a) Ceriagrion ? erubescens Sel., Timor, und b) Xiphiagrion cyanomelas Sel., Flores (oben medianes Blatt, unten laterales Blatt). 
Kiemenblätter gross, halbdurchscheinend, mit einer ganz kleinen Spitze endend, Tracheenverzweigung gut sichtbar (durch Alkohol ziemlich opak und milchig getrübt); deutlich quergeteilt in einen basalen Teil, dessen Ränder ganz kleine, enggestellte Dörnchen tragen und einen distalen, an den Rändern völlig unbehaarten Teil. Teilungslinie sehr schief (Randbedornung ungleich lang) und scharf markiert durch eine einzige, nach dem Rande zu stark verschmälerte, diffuse, braune Querbinde. Tracheen reich verzweigt (Fig. 17 b).

Larve von Java. - Form und Zeichnung ganz ähnlich floresischem Exemplar. Jederseits wie bei dieser 4 mentale und 5 laterale Borsten, die aber deutlich kürzer sind. Lab.-Sl. mit dem lateralen Anteil deutlicher abgeschnitten, die Endzähne reduziert, die Zwischenräume viel weniger eingeschnitten; der mediane Anteil mit relativ längerem, den lateralen Teil überragendem Endzahn. Beweglicher Endhaken dicker und kürzer als beim Flores-Exemplar (Fig. 16b).

Larve von Celebes. - Etwas grösser als die vorher besprochenen Larven, sonst fast identisch. Jederseits 4 (oder seltener 5) mentale, und 6 laterale Borsten. Lab.-Sl. sehr ähnlich den Exemplaren von Flores, lateraler Anteil deutlich und stark gezähnt (Fig. $16 d$ ). Tracheenkiemen etwas breiter und am Ende nur mit ganz kurzer Spitze.

Nach Struktur und Borstenbesatz des Labiums, sowie nach dem Bau der Kiemenblätter, zeigt diese Larve unstreitige Beziehungen zu denen der Genera Enallagma, Aciagrion und in gewissem Grade auch mit Ischnura. Die engen Verwandtschaftsbeziehungen zwischen Xiphiagrion und den höher spezialisierten Agrioniden, also nicht mit der Pseudagrion-Gruppe, werden also durch die Larve bestätigt.

\section{Ceriagrion erubescens (Selys) (?).}

(Fig. $17 a, 18-19$.

Material: 1 o Larve (vorletztes Stadium ?) von Timor, ohne weitere Angaben, Mrs. M. E. Walsh leg.

Körper gedrungen, opak; Färbung licht braungelb, fast ohne Zeichnung, Kopf oben mehr orangegelb. Augen schwarzbraun verfärbt. 
Körperlänge $12,6 \mathrm{~mm}$, medianes Kiemenblatt 4,2, laterales Blatt 4,4 $\mathrm{mm}$ lang.

Kopf sehr breit und flach, vorn ohne deutliche Frontalleiste. Antennen lang (die einzelnen Glieder wurden an diesem jungen Exemplar nicht gemessen). Labium kurz und breit, das 1. Beinpaar nach hinten kaum überragend. Lab.-Ml. flach-dreieckig vorspringend, am Rande microscopisch gewellt und dicht mit ganz kurzen Dörnchen besetzt. Seitenränder mit jederseits etwa 10 Dörnchen. Jederseits nur eine kräftige mentale Borste und eine unregelmässige, schiefe Reihe von 5-6 ganz feinen Borstenhaaren; ebenso

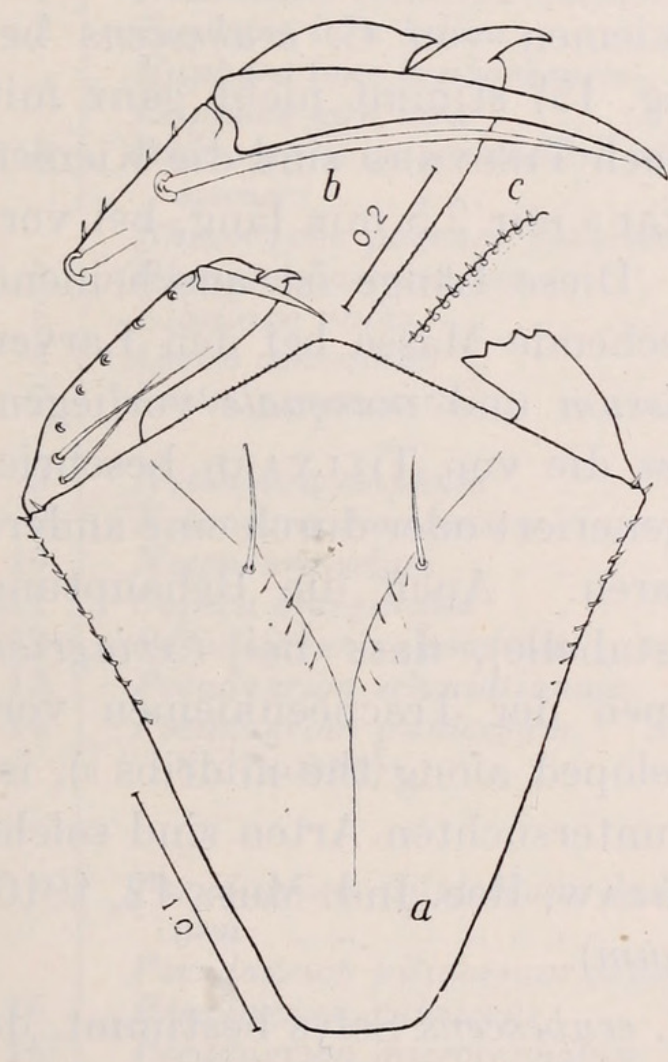

FIG. 19.

Ceriagrion ? erubescens Selys, Timor.

a) Labium von der Innenseite; b) Endteil der Seitenlappen desselben; c) Borstenbesatz des Randes der Mittellappen, stärker vergrössert.

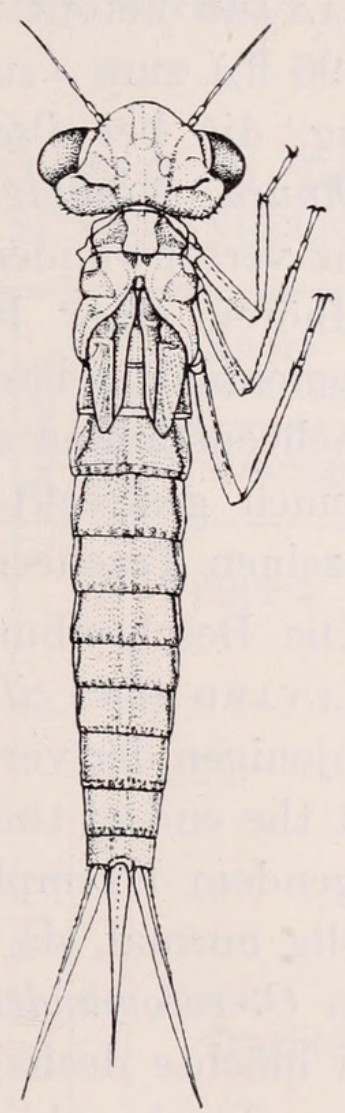

Fig. 18.

Ceriagrion erubescens

Selys, Timor.

Larve im (?) vorletzten Stadium.

7 laterale Borsten. Lab.-Sl. deutlich zweigeteilt, der laterale Anteil aussen völlig gerundet, medianwärts mit deutlichem Endzahn; der mediane Teil mit kräftigem, hakenförmigem Endzahn. Beweglicher Endhaken ziemlich stark (Fig. 19).

Kiemenblätter halbdurchsichtig, nur am Rande mit diffusen, isoliert stehenden, bräungelblichen Fleckchen. Trache- 
enverzweigung wie bei den anderen bekannten Arten der Gattung sehr charakteristisch und reichlich entwickelt. Form und Bedornung der Kiemen siehe Figur $17 a$.

Die Tracheenkiemen von Ceriagrion gehören, wie schon von Tillyard betont wurde (Proc. Linn. Soc. N. S. Wales, 42, 1917, p. 96 ff.) zum "subnodaten » Typus; die ursprüngliche Einschnürung, die bei Pseudagrion und Verwandten ganz deutlich, bei Ischnura, Xiphiagrion u. A. nur schwach vorhanden ist, ist hier ganz verschwunden und die Lage des Nodus ist jetzt nur durch das Aufhören einer Reihe ganz kurzer Setae am Aussenrand der Kiemenblätter bestimmt. Die Hauptverzweigungen der medianen Tracheenstämme sind länger und mehr in der Längsrichtung der Kiemen gestreckt und die büschelähnlichen Verzweigungen der einzelnen Tracheenäste sind viel weniger deutlich.

Die Beschreibung der Tracheenkiemen von $C$. erubescens bei Tillyard (loc. cit., p. 97, Pl. 2, fig. 15) stimmt nicht ganz mit denjenigen der vorliegenden Art. Nach Tillyard sind die Kiemen " at the end of the penultimate instar " nur 2,5 mm lang, bei vorliegendem Exemplar über $4 \mathrm{~mm}$ ! Diese Länge ist anscheinend völlig normal, da mir ganz entsprechende Masse bei den Larven von $C$. coromandelianum, praetermissum und inaequale vorliegen. Ich möchte deshalb annehmen, dass die von Tillyard beschriebenen Tracheenkiemen entweder regeneriert oder durch eine andere Ursache nicht gut ausgebildet waren. Auch die Behauptung Tillyards (loc. cit., p. 97, Genustabelle), dass bei Ceriagrion keine Dornen längs den Mittelrippen der Tracheenkiemen vorhanden sein sollen ("no spines developed along the midribs»), ist sicher unrichtig; bei allen von mir untersuchten Arten sind solche deutlich vorhanden (siehe auch Laid law, Rec. Ind. Mus., 12, 1916, p. 134, Larve von C. coromandelianum).

Unsere Art wurde vorläufig als $C$. erubescens Selys bestimmt, da nur diese Species von den Nachbarinseln (Aroe, südliches Neuguinea, Nordaustralien) bekannt geworden ist.

62. Anax gibbosulus (Ramb.).

M a te ria 1: 6 Exemplare (ult), W. Flores, Kratersee Wai Sano, 650 m, XI. 1929, J. K. DE Jong leg. - 5 Exemplare (jung: 
verschiedenes Alter), Timor, ohne weitere Angabe, Mrs. M. E. WaLsh leg. und don.

Diese Larven sollen an anderer Stelle, zusammen mit einem grösseren Material einer Reihe weiterer Anax-Formen des malayischpapuanischen Gebietes zusammenfassend bearbeitet werden.

TABELLARISCHE ÜBERSICHT ÜBER DIE VERBREITUNG DER EINZELNEN FORMEN AUF DEN KLEINEN SUNDA-INSELN

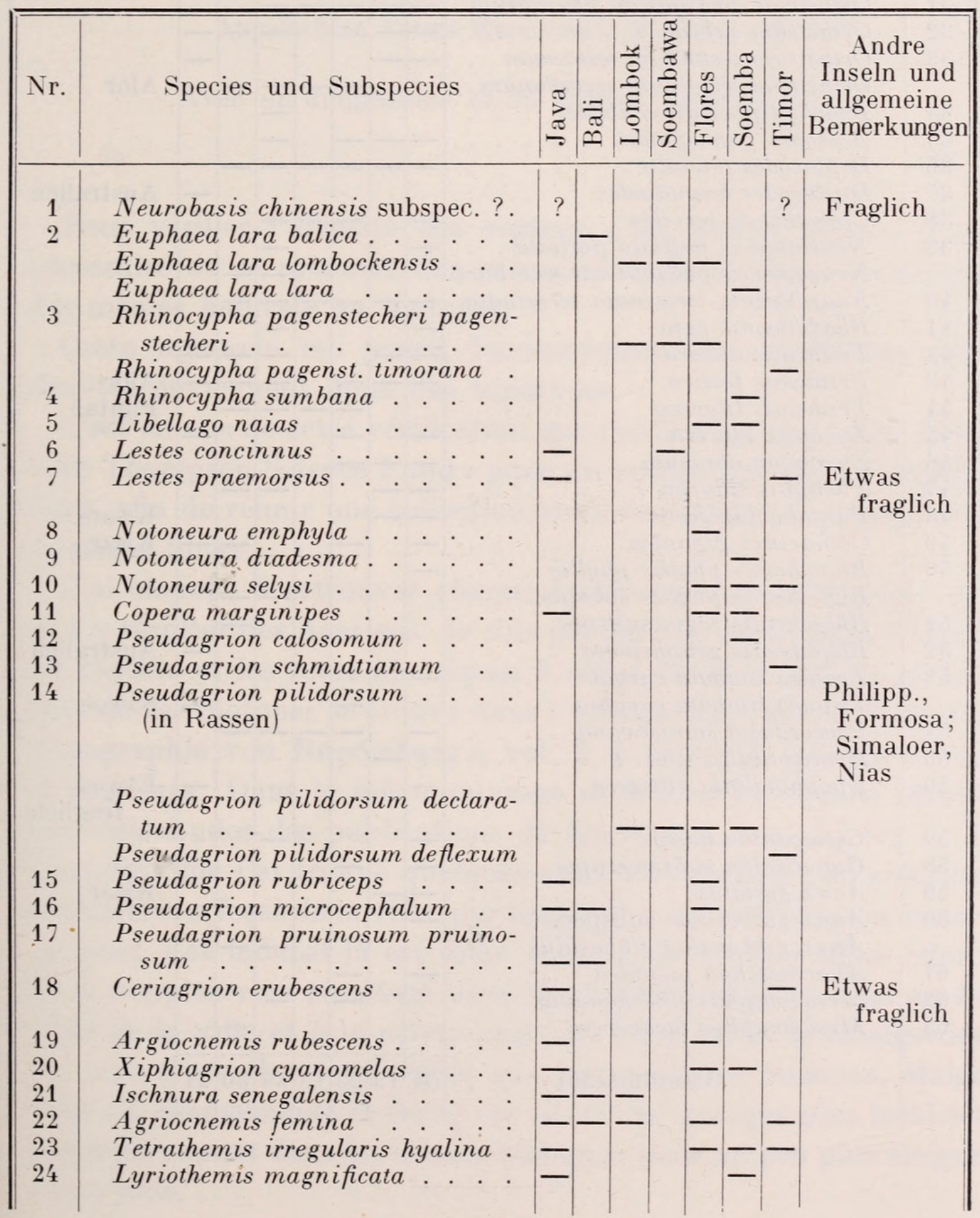




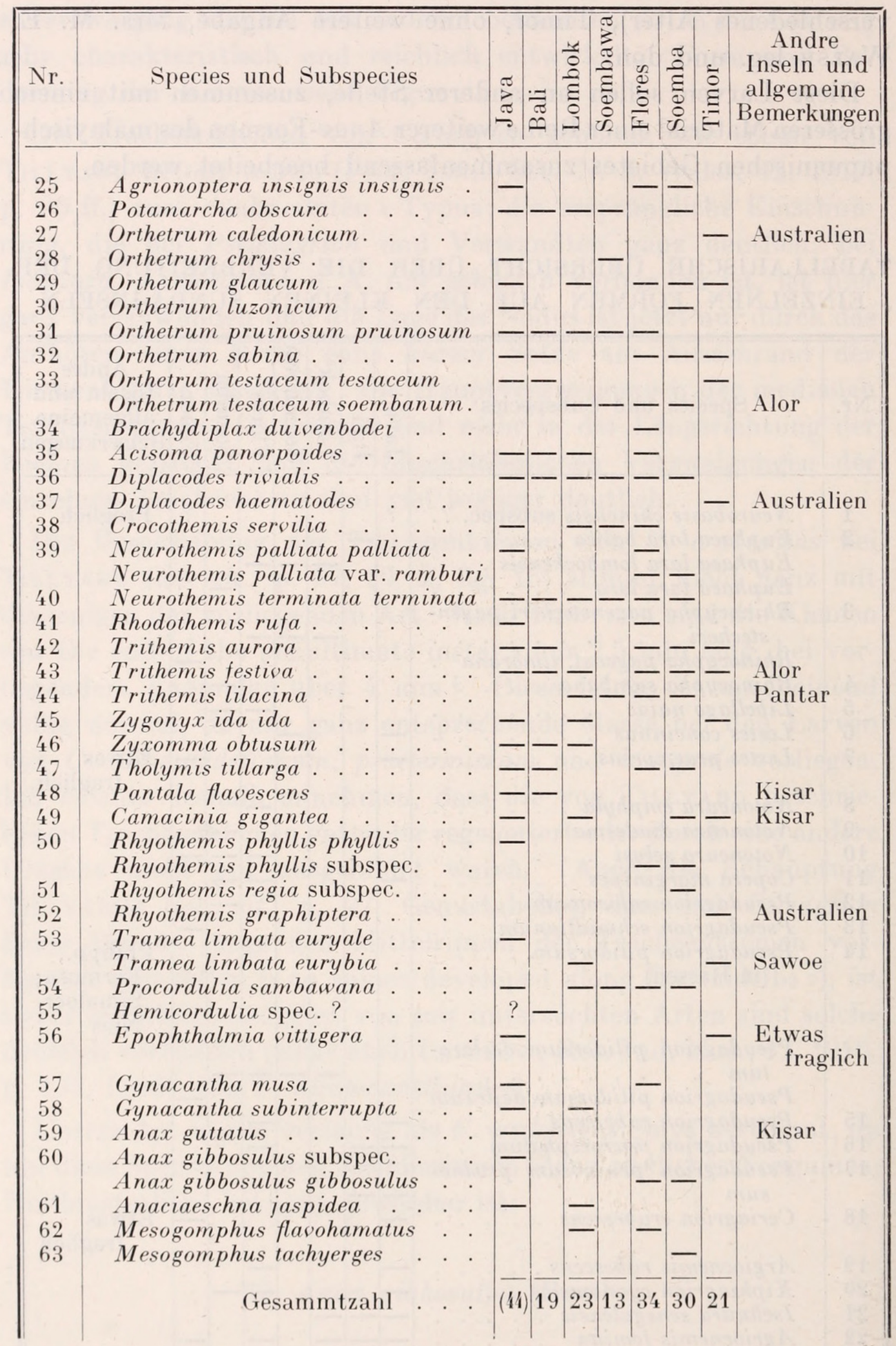




\section{$2 \mathrm{BHL}$ Biodiversity Heritage Library}

Lieftinck, M. A. 1936. "Die Odonaten der Kleinen Sunda-Inseln." Revue suisse de zoologie 43, 99-160. https://doi.org/10.5962/bhl.part.145462.

View This Item Online: https://www.biodiversitylibrary.org/item/148563

DOI: https://doi.org/10.5962/bhl.part.145462

Permalink: https://www.biodiversitylibrary.org/partpdf/145462

\section{Holding Institution}

American Museum of Natural History Library

\section{Sponsored by}

BHL-SIL-FEDLINK

\section{Copyright \& Reuse}

Copyright Status: In copyright. Digitized with the permission of the rights holder.

Rights Holder: Muséum d'histoire naturelle - Ville de Genève

This document was created from content at the Biodiversity Heritage Library, the world's largest open access digital library for biodiversity literature and archives. Visit BHL at https://www.biodiversitylibrary.org. 